\title{
Fenugreek (Trigonella Foenum-Graecum) Seed Flour and Diosgenin Preserve Endothelium-Dependent Arterial Relaxation in a Rat Model of Early-Stage Metabolic Syndrome
}

\author{
Katalin Szabó ${ }^{1}$, Rudolf Gesztelyi ${ }^{1}$ (i), Nóra Lampé ${ }^{1}$, Rita Kiss ${ }^{1}$ (i), Judit Remenyik ${ }^{2}$, \\ Georgina Pesti-Asbóth ${ }^{2}$, Dániel Priksz ${ }^{1}$, Zoltán Szilvássy ${ }^{1, \dagger}$ and Béla Juhász ${ }^{1, *, \dagger}$ \\ 1 Department of Pharmacology and Pharmacotherapy, Faculty of Medicine, University of Debrecen, \\ Nagyerdei krt. 98, H-4032 Debrecen, Hungary; szabo.katalin@pharm.unideb.hu (K.S.); \\ gesztelyi.rudolf@pharm.unideb.hu (R.G.); lampenori@gmail.com (N.L.); kiss.rita@med.unideb.hu (R.K.); \\ priksz.daniel@pharm.unideb.hu (D.P.); szilvassy.zoltan@med.unideb.hu (Z.S.) \\ 2 Institute of Food Technology, Faculty of Agricultural and Food Sciences and Environmental Management, \\ University of Debrecen, Boszormenyi ut 138, H-4032 Debrecen, Hungary; remenyik@agr.unideb.hu (J.R.); \\ georgina.asboth@gmail.com (G.P.-A.) \\ * Correspondence: juhasz.bela@med.unideb.hu; Tel.: +36-52-427-899 \\ + These authors contributed equally to this work.
}

Received: 30 December 2017; Accepted: 5 March 2018; Published: 10 March 2018

\begin{abstract}
Fenugreek is a common herb possessing several bioactive components including diosgenin. Here, dietary fenugreek seed flour and diosgenin were evaluated on a model of endothelium-dependent vasorelaxation by abdominal aortas isolated from rats receiving high-fat, high-sugar diet (HFHSD). 60 male Wistar rats were randomized into six groups: (i) negative control getting conventional rat feed regimen; (ii) positive control receiving HFHSD; (iii) a test group fed $2 \mathrm{~g} / \mathrm{kg}$ bw/day fenugreek seed flour (containing $10 \mathrm{mg} / \mathrm{kg}$ bw/day diosgenin) + HFHSD; (iv) three test groups fed 1, 10 and $50 \mathrm{mg} / \mathrm{kg}$ bw/day diosgenin + HFHSD. Alimentary treatments were carried out for six weeks. The abdominal aortas were isolated, and $2 \mathrm{~mm}$ wide rings were sectioned off and mounted at a resting tension of $10 \mathrm{mN}$ in organ baths containing Krebs solution $\left(36{ }^{\circ} \mathrm{C}\right)$ exposed to $95 \% \mathrm{O}_{2}$ and $5 \% \mathrm{CO}_{2}$. After 60-min incubation, a norepinephrine concentration-response $(\mathrm{E} / \mathrm{c})$ curve was generated to determine their half-maximal effective concentration $\left(\mathrm{EC}_{50}\right)$ value. After 60-min wash-out, a pre-contraction with norepinephrine $\mathrm{EC}_{50}$ was made, followed by an acetylcholine E/c curve. Plasma glutathione levels, glutathione-handling enzyme activities and blood antioxidant capacities were also determined. HFHSD significantly decreased the dilatory response to acetylcholine and increased plasma glutathione levels and these effects were significantly reversed by fenugreek seed flour, 10 and $50 \mathrm{mg} / \mathrm{kg}$ bw/day diosgenin. Both fenugreek and diosgenin treatments prevent HFHSD-induced endothelial dysfunction and redox changes. As fenugreek treatment was more effective at lower acetylcholine concentrations than diosgenin treatments, components of fenugreek other than diosgenin may contribute to the beneficial effects of dietary fenugreek seed flour.
\end{abstract}

Keywords: endothelial dysfunction; metabolic syndrome; obesity; type 2 diabetes mellitus; fenugreek; Trigonella foenum-graecum; diosgenin; endothelium-dependent vasorelaxation; Wistar rat

\section{Introduction}

Metabolic syndrome (MetS) is a group of metabolic disorders characterized by the presence of at least three of five pathological conditions, described as follows: central obesity, hypertension, hyperglycemia, hypertriglyceridemia and decreased level of high-density lipoprotein (HDL) $[1,2]$. 
MetS is one of the most prevalent and rapidly increasing challenges to public health worldwide, with onset and pathogenesis associated with frequent sedentary lifestyle choices and high calorie intake in affluent societies. MetS patients have a five-fold higher risk of developing type 2 diabetes mellitus (T2DM) and two-fold risk for cardiovascular diseases (CVD) than the general human population $[3,4]$. A major commonality of these pathologies is that they all engender impairment of endothelial function. Endothelial dysfunction (ED) forms the basis of atherosclerosis, which is the most important risk factor for CVD [5,6].

Although the vascular endothelium consists only of a thin monolayer of cells covering the inner surface of blood vessel wall, this tissue plays a crucial role in maintenance of a normal circulation. Beyond its barrier function, endothelium acts as a paracrine organ producing a number of transmitter molecules that contribute to the regulation of a wide range of processes including hemostasis, inflammation, vascular proliferation and vascular tone [7,8]. Endothelial cells synthesize both vasodilators (such as endothelium-derived relaxing factor (nitric oxide: NO), endothelium-derived hyperpolarizing factor, prostacyclin (PGI2)) and vasoconstrictor compounds (e.g., endothelins and leukotrienes) $[9,10]$. Certain metabolic, hormonal and homeostatic conditions, including hyperglycemia, hyperinsulinemia, hypertension, obesity, decreased level of high-density lipoprotein cholesterol (HDL), increased levels of insulin-like growth factor 1, fatty acids, triglycerides, low-density lipoprotein cholesterol (LDL), angiotensin II and plasminogen activator inhibitor-1, impair the barrier and regulatory functions of endothelial cells and thereby lead to ED. A major consequence of ED is that the balance between vasoconstriction and vasorelaxation is disrupted resulting in detrimental vasoconstriction that progresses into hypertension [11]. A further consequence of ED is a concomitant disharmony between coagulation and fibrinolysis, which can lead to enhanced thrombus formation. These deleterious processes, when added to other effects of hypertension, create conditions that favor atherosclerosis and elevated risk for cardiovascular events, especially stroke and acute myocardial infarction [12]. The most important underlying molecular mechanisms leading to ED are decreased production and/or increased degradation of $\mathrm{NO}$, diminished responsiveness to $\mathrm{NO}$, depletion of $\mathrm{NADPH}$, increased $\mathrm{NADH} / \mathrm{NAD}^{+}$ratio, elevated levels of protein kinase $\mathrm{C}$ and advanced glycation end products; in general: increased oxidative stress and decreased antioxidant capacities [13].

The complexity of overlapping signaling pathways leading to ED has made identification of the primary triggering events problematic. A schematic representation of signaling pathways contributing to ED, made by Hsueh et al., provided enhanced clarity by delineating these processes in relation to progression of insulin resistance. This graphic construct suggests that hyperinsulinemia may act as a "zero point" event, which alters endothelial function in ways that progress into MetS. MetS, especially with obesity, increases systemic inflammation, oxidation of NO and LDL cholesterol, thereby increasing the risk of thrombosis, a condition that also adversely affects endothelial function. MetS is associated with impaired glucose tolerance and T2DM onset, two conditions that increase the risk of atherosclerosis [14].

In the present report, fenugreek seed flour was investigated as a possible countermeasure to the above-mentioned pathological changes, with special regard to the restoration of endothelial function. The rationale for selecting this plant is based on its "generally recognized as safe" (GRAS) status as a component of human diet, along with its known antidiabetic properties and wide availability. Fenugreek (Trigonella foenum-graecum) is one of the most commonly used medicinal herbs in the prevention and treatment of T2DM in many East Asian cultures. A component of this plant, diosgenin, along with 4-isohydroxyleucin and galactomannan, are the components thought to be the most responsible for the beneficial effects of fenugreek on MetS and T2DM [15]. Diosgenin is a phytosteroid sapogenin that can be chemically converted into several medically used steroid products, notably progesterone, pregnenolone and cortisone. Although metabolic effects of fenugreek have been widely studied, little definitive data has been published regarding its effects on the vasculature. It has, nevertheless, been noted that aqueous extracts of fenugreek leaf [16] and alcoholic extracts of fenugreek seed [17] were found to have beneficial effects in a streptozotocin-induced diabetic rat 
model. In contrast to fenugreek, several investigations dealt with diosgenin, primarily focusing on its ability to improve the condition of vasculature and/or endothelium in diabetic rats [18-24]. However, the underlying cellular and molecular mechanisms concerning diosgenin's effects have remained to be defined at the time of this writing.

For the present investigation, a rat model of early-stage MetS was used. Wistar rat is a widely used experimental model of the disturbed carbohydrate and/or lipid metabolism [25,26].

\section{Results}

\subsection{Characteristics of the Animal Model}

During the 6-week dietary treatment, rats showed a moderate (and statistically non-significant) body weight gain in every experimental group. The average weight gain was the biggest in the fenugreek group (treated with fenugreek seed flour: $85 \mathrm{~g}$ ) followed by the positive control group (received HFHSD only: $69.9 \mathrm{~g}$ ), $50 \mathrm{mg}$ diosgenin group (got $50 \mathrm{mg} / \mathrm{kg}$ bw/day diosgenin: $55.9 \mathrm{~g}$ ), $10 \mathrm{mg}$ diosgenin group (received $10 \mathrm{mg} / \mathrm{kg} \mathrm{bw} /$ day diosgenin: $40.6 \mathrm{~g}$ ) and $1 \mathrm{mg}$ diosgenin group (got $1 \mathrm{mg} / \mathrm{kg} \mathrm{bw} /$ day diosgenin: $35.4 \mathrm{~g}$ ), while the body weight gain was the smallest in the negative control group (kept conventionally: $30.9 \mathrm{~g}$ ) (Figure 1a).

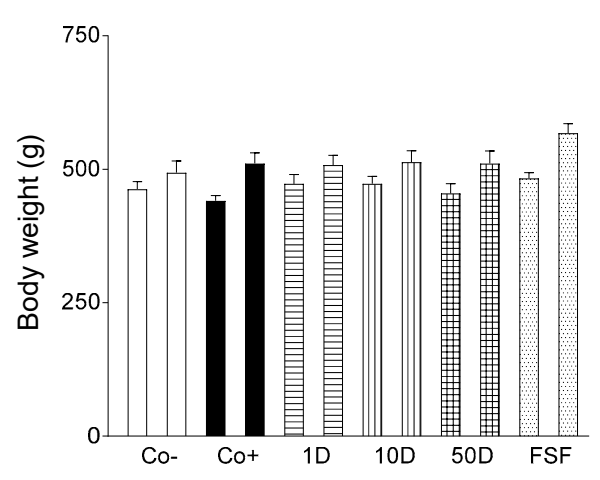

(a)

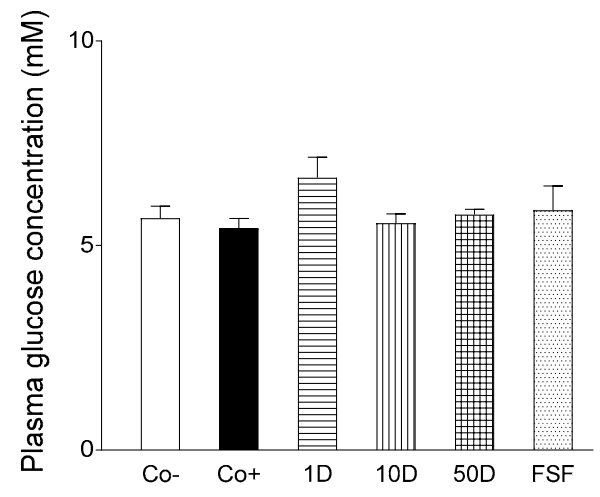

(b)

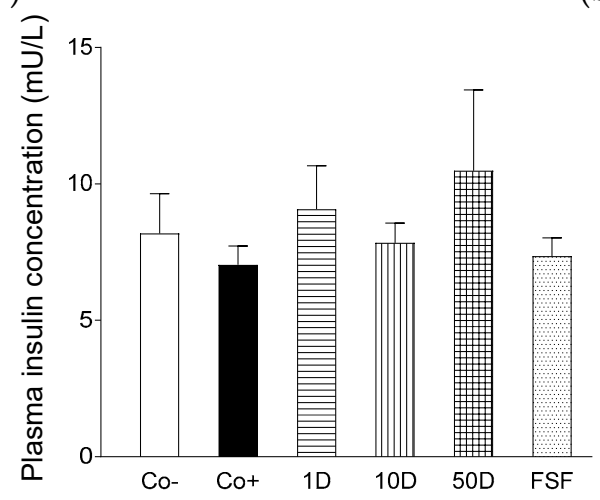

(c)

Figure 1. The effect of high-fat, high-sugar diet (HFHSD) (positive control: $\mathrm{Co}+$ ), $2 \mathrm{~g} / \mathrm{kg}$ bw/day fenugreek seed flour in addition to HFHSD (FSF), 1, 10 and $50 \mathrm{mg} / \mathrm{kg}$ bw/day diosgenin in addition to HFHSD (1D, 10D and 50D, respectively) on the body weight (a), fasting plasma glucose level (b) and fasting plasma insulin level (c) of Wistar rats. The negative control group ( $\mathrm{Co}-$ ) consisted of rats receiving conventional rat food and tap water. In the panel (a), the left one of columns with the same color and pattern indicates the initial body weight, while the right one shows the body weight after the 6-week dietary treatment. The columns represent the average values of the given groups (+SEM). 
Neither fasting plasma glucose concentrations nor fasting plasma insulin levels, measured after the six-week dietary treatment, differed significantly among the groups (Figure 1b,c).

These results indicate that, in this model, no obesity or insulin resistance, two important pathological conditions characteristic of MetS, developed. Consistently, no significant effect of alimentary fenugreek or diosgenin treatment on the body weight and glucose homeostasis could be observed.

\subsection{Response to Norepinephrine}

The maximal contractile forces that evolved in the presence of the different NE concentrations did not differ significantly among the six groups (Figure 2). The statistically non-significant increase in the NE-susceptibility of the positive control group (subjected to HFHSD only) might indicate a moderate decrease in the basal production and/or availability of NO in comparison with that/those of the negative control group (encompassing rats kept conventionally). If that were the case, the applied alimentary fenugreek and diosgenin treatments might slightly improve vascular NO homeostasis (Figure 2).

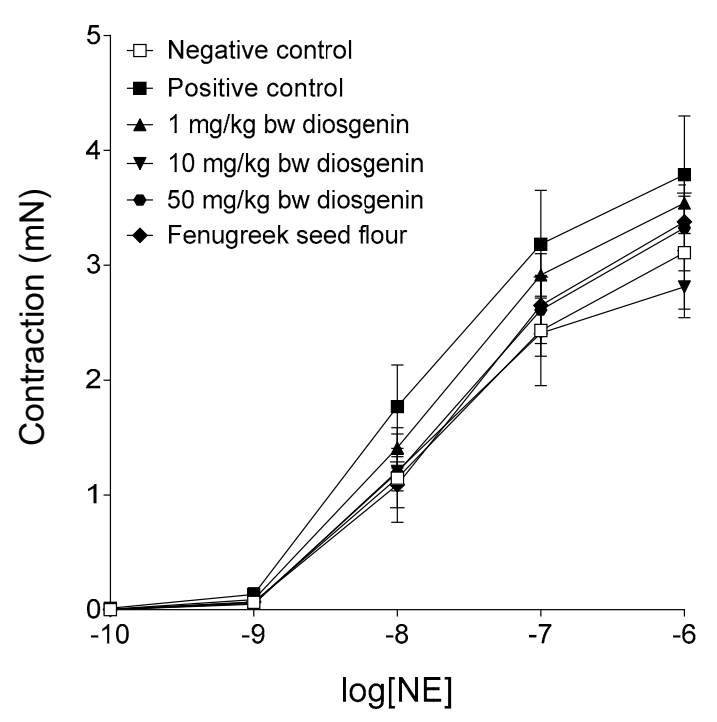

Figure 2. The effect of norepinephrine (NE) on the abdominal aorta isolated from rats treated with dietary fenugreek seed flour or different doses of diosgenin in addition to high-fat, high-sugar diet (HFHSD), and from rats forming the positive (receiving HFHSD only) and negative (getting conventional rat food and tap water) controls. The axis $x$ shows the common logarithm of molar concentration of $\mathrm{NE}$, while the axis $y$ indicates the contractile force of the aortic rings (over the resting level). The length of the rings was the same throughout the study. The symbols represent the effect of $\mathrm{NE}$ averaged within the groups ( \pm SEM).

\subsection{Response to Acetylcholine}

In the negative control group (consisting of rats kept conventionally), 10-100 $\mu \mathrm{mol} / \mathrm{L}$ acetylcholine (Ach) could totally abolish the pre-contraction of aortic rings elicited by $\mathrm{NE}$ (used in $\mathrm{EC}_{50}$ concentration). In contrast, responses to Ach in the positive control group (receiving HFHSD only) showed a significant decrease (at 10, 100 and $1000 \mu \mathrm{mol} / \mathrm{L}$ Ach concentrations) when compared with those in the negative control group (Figure 3a). Thus, despite the absence of obesity and insulin resistance reflected by the results presented above (Figure 1), our HFHSD rat model displayed impaired endothelial function characteristic of disturbed carbohydrate and/or lipid metabolism.

The $2 \mathrm{~g} / \mathrm{kg}$ bw/day fenugreek seed flour treatment significantly improved the response to Ach (even at relatively low Ach concentrations), almost totally preventing the deteriorative effect of HFHSD (Figure 3b). Treatment with diosgenin, a fenugreek component thought to be important regarding 
the beneficial effects of fenugreek preparations, can fairly mimic the action of fenugreek seed flour treatment in the present model. Although $1 \mathrm{mg} / \mathrm{kg}$ bw/day diosgenin failed to reach a statistically significant beneficial effect (due to the high scatter in the results reflecting very different individual responses to Ach in the $1 \mathrm{mg}$ diosgenin group) (Figure 3c), 10 and $50 \mathrm{mg} / \mathrm{kg} \mathrm{bw} /$ day diosgenin significantly augmented the Ach-induced relaxation (especially at medium and high Ach levels) in comparison with the positive control group (Figure 3d,e). Nevertheless, responses to Ach in the fenugreek and diosgenin groups did not differ from one another in a statistically significant manner.

It should be noted that the effect of $2 \mathrm{~g} / \mathrm{kg}$ bw/day fenugreek seed flour treatment (equivalent to $10 \mathrm{mg} / \mathrm{kg} \mathrm{bw} /$ day diosgenin treatment regarding its diosgenin content) showed two interesting differences in comparison with the action of diosgenin treatments. First, the shape of Ach concentration-response (E/c) curve was the least regular in the fenugreek group, probably owing to the complex effects afforded by the numerous components of fenugreek seed flour. Second, only fenugreek treatment could significantly enhance the relaxation at $10 \mathrm{nmol} / \mathrm{L}$ Ach concentration (a relatively low value), although the maximal relaxation evoked by Ach in the fenugreek group was (non-significantly) smaller than that in the negative control and diosgenin groups. It is also interesting that average effects of the different diosgenin treatments on the response to Ach were quite similar to one another, the increase of diosgenin dose predominantly reduced the scatter of the results, i.e., it homogenized the response to Ach. For further evaluation of the Ach E/c curves, see Appendix A.

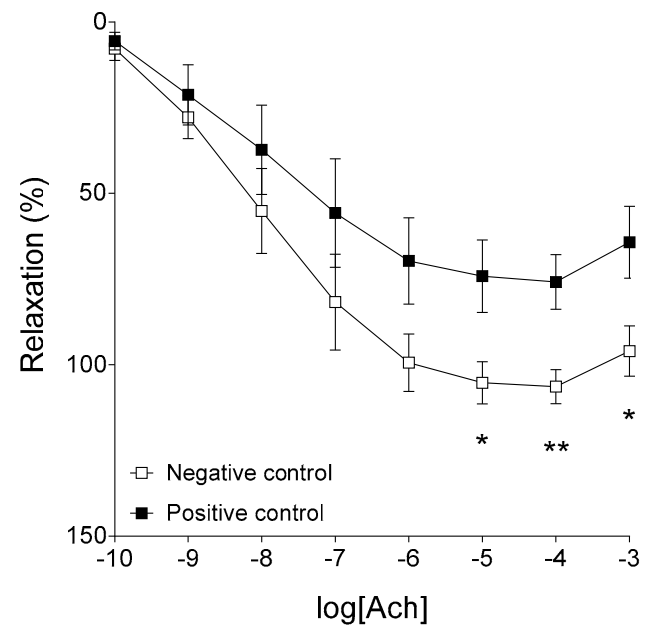

(a)

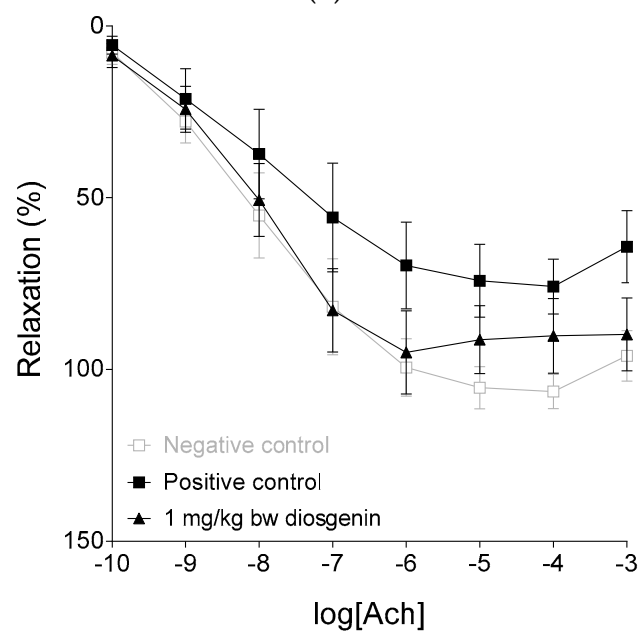

(c)

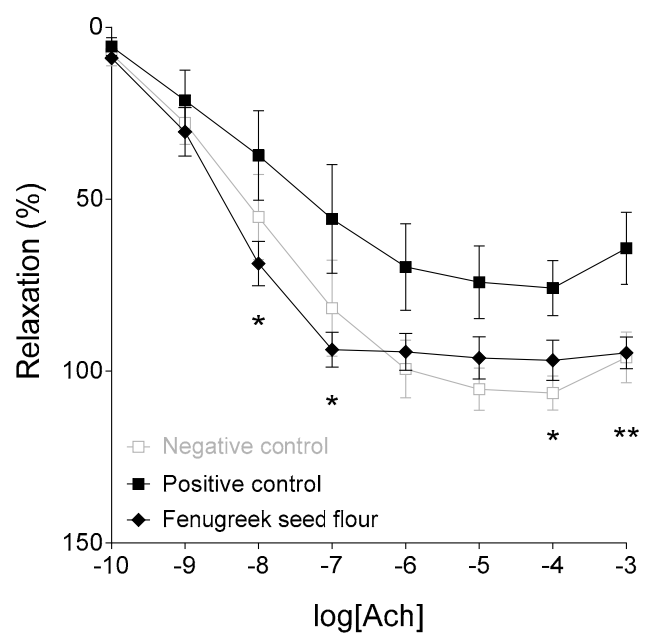

(b)

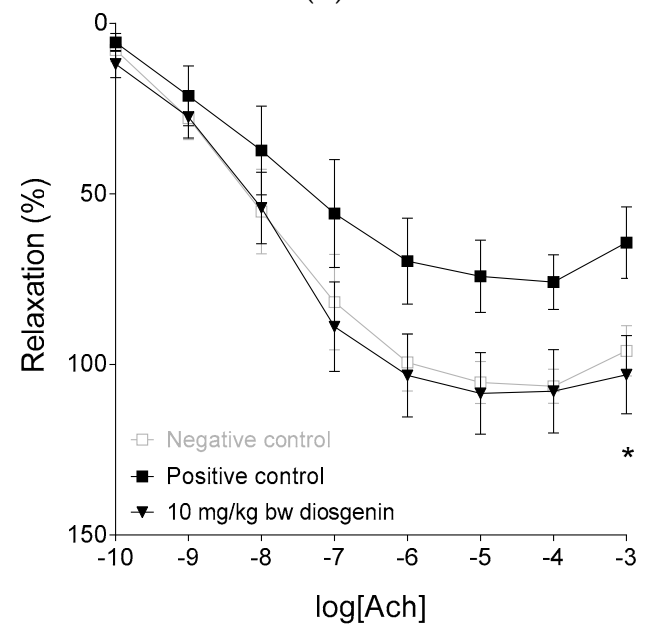

(d)

Figure 3. Cont. 


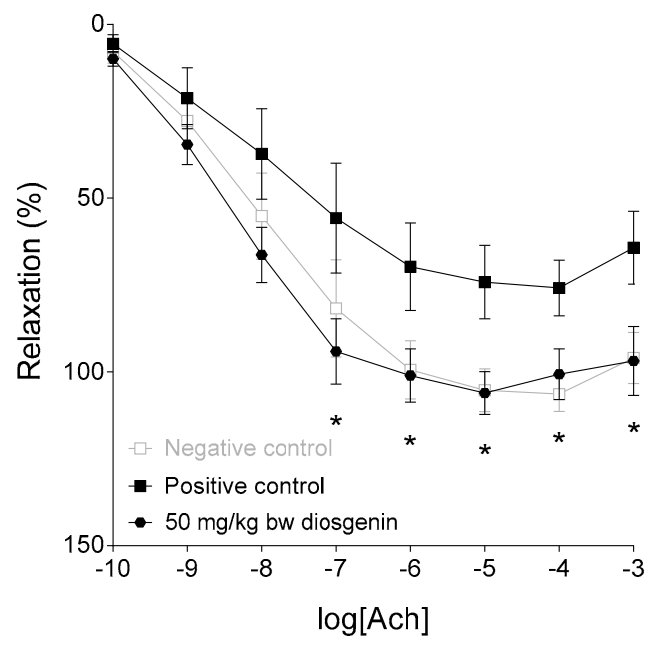

(e)

Figure 3. The effect of acetylcholine (Ach) on the abdominal aorta isolated from rats treated with dietary fenugreek seed flour (panel (b)) or different doses of diosgenin in addition to high-fat, high-sugar diet (HFHSD) (panel (c-e)), and from rats forming the positive (receiving HFHSD only) and negative (receiving conventional rat food and tap water) controls (panel (a)). All aortic rings underwent a pre-contraction evoked by norepinephrine (NE) before the administration of Ach. The axis $x$ shows the common logarithm of molar concentration of Ach, while the axis $y$ indicates the effect as a percentage decrease of the initial contractile force of aortic rings. The symbols represent the effect of Ach averaged within the groups $( \pm \mathrm{SEM})$. Asterisks denote the significance level of differences between groups indicated with black colored symbols and lines $\left(*: p<0.05 ;{ }^{* *}: p<0.01\right)$.

\subsection{Results of Assays for Blood Redox Status}

Results of the present investigation concerning the changes in plasma glutathione levels, glutathione-handling enzyme activities and antioxidant capacity in response to the different dietary treatments allow us to make some assumptions. The HFHSD tended to shift the oxidoreductive balance to the oxidative direction in the blood, indicated by an increase in oxidized glutathione level of positive control group (receiving only HFHSD) as compared to the negative control group (getting normal diet) (Figure 4a). Probably as a result of compensatory processes, the oxidative stress caused by HFHSD also increased the level of the reduced form of glutathione in the plasma of positive controls (Figure $4 \mathrm{~b}$ ) that led to a practically unchanged reduced to oxidized glutathione ratio (Figure 4c). It is clearly seen, furthermore, that the treatment with either diosgenin or fenugreek dramatically decreased the concentration of glutathione, equally affecting both of its forms (Figure 4). This phenomenon could also be considered as a result of counteracting processes against oxidative stress caused by HFHSD, if assuming that diosgenin and some compounds of fenugreek (including diosgenin itself) acted as effective antioxidants rendering sufficient oxidoreductive balance even at low glutathione plasma levels. 


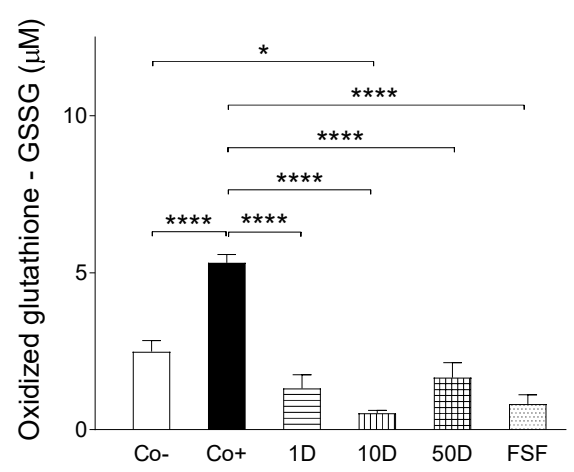

(a)

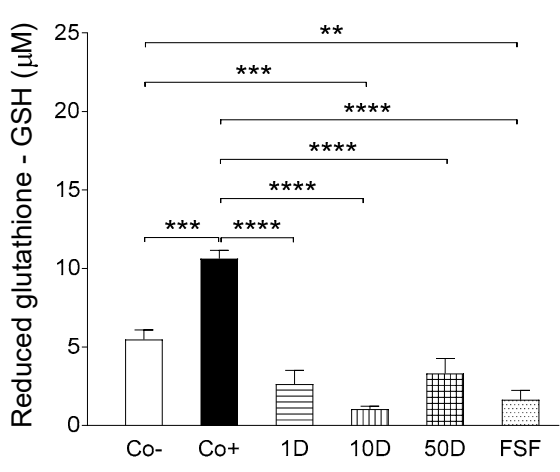

(b)

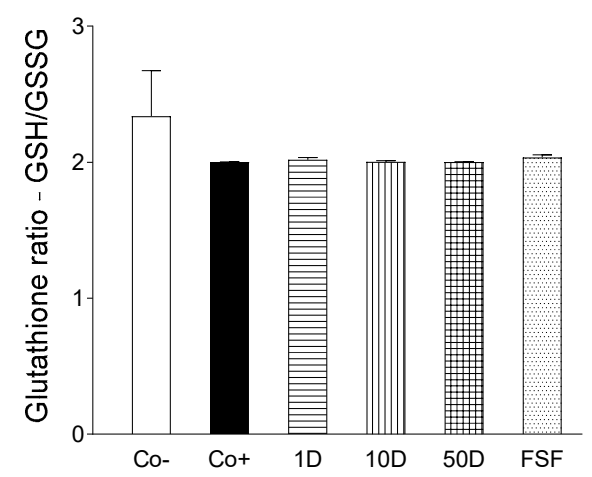

(c)

Figure 4. The effect of high-fat, high-sugar diet (HFHSD) (positive control: $\mathrm{Co}+$ ), $2 \mathrm{~g} / \mathrm{kg}$ bw /day fenugreek seed flour in addition to HFHSD (FSF), 1, 10 and $50 \mathrm{mg} / \mathrm{kg} \mathrm{bw} /$ day diosgenin in addition to HFHSD (1D, 10D and 50D, respectively) on plasma levels of the oxidized (a) and reduced (b) forms of glutathione, furthermore on the ratio of reduced to oxidized glutathione (c) in Wistar rats. The negative control group $(\mathrm{Co}-)$ consisted of rats receiving conventional rat food and tap water. The columns represent the average values of the given groups (+SEM). Asterisks indicate the significance level of differences between groups $\left({ }^{*}: p<0.05 ;{ }^{* *}: p<0.01 ;{ }^{* * *}: p<0.001 ;{ }^{* * *}: p<0.0001\right)$.

Although activities of glutathione peroxidase, an enzyme which reduces the peroxide $(\mathrm{O}-\mathrm{O})$ moiety to an $\mathrm{O}-\mathrm{H}$ moiety via oxidizing the reduced form of glutathione, did not show considerable differences among the groups (Figure 5a), activities of glutathione reductase, which regenerates the oxidized glutathione to a reduced one, proved to be significantly lower in the diosgenin- and fenugreek-treated groups as compared to both the negative and positive controls (Figure 5b). This latter finding corroborates the assumption described above, i.e., diosgenin and perhaps some other fenugreek compounds are effective antioxidants that decrease the need for glutathione. The counterbalancing function of glutathione (and possibly other endogenous oxidoreductive) system(s), which seem(s) to maintain a dynamic functional equilibrium with exogenous factors (e.g., dietary diosgenin), may be reflected in the finding that the antioxidant capacities of lipid- (Figure 6a) as well as water-soluble (Figure 6b) substances of the blood did not differ in a considerable way among the experimental groups receiving different dietary treatments. 


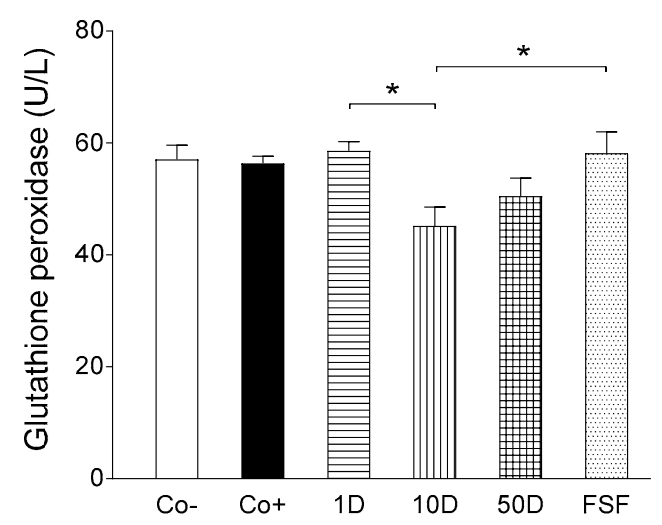

(a)

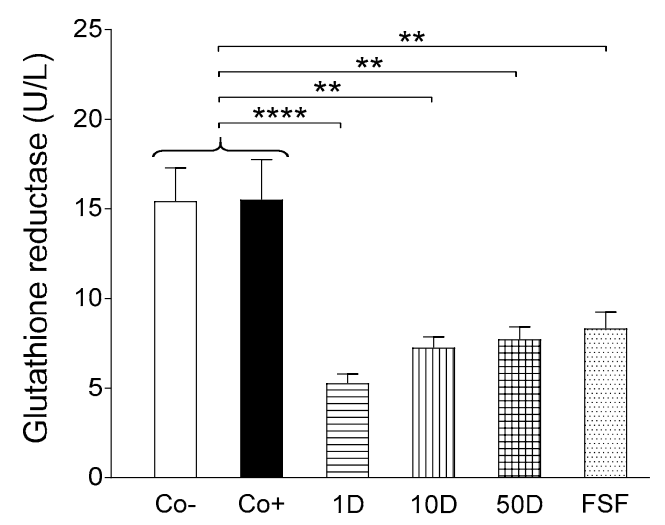

(b)

Figure 5. The effect of high-fat, high-sugar diet (HFHSD) (positive control: $\mathrm{Co}+$ ), $2 \mathrm{~g} / \mathrm{kg}$ bw/day fenugreek seed flour in addition to HFHSD (FSF), 1, 10 and $50 \mathrm{mg} / \mathrm{kg}$ bw/day diosgenin in addition to HFHSD (1D, 10D and 50D, respectively) on plasma activities of two major glutathione-handling enzymes, glutathione peroxidase (a) and glutathione reductase (b), in Wistar rats. The negative control group $(\mathrm{Co}-)$ consisted of rats receiving conventional diet. The columns represent the average values of the given groups (+SEM). Asterisks indicate the significance level of differences between groups $\left.{ }^{*}: p<0.05 ;{ }^{* *}: p<0.01 ;{ }^{* * *}: p<0.0001\right)$.

In summary, diosgenin (and maybe some other components of fenugreek seed) appear(s) to substitute the endogenous antioxidant factors (including glutathione) to maintain the vascular redox balance. So, changes in endogenous antioxidant mechanisms (Figures 4-6) can be considered to be rather compensatory responses to the presence of exogenous antioxidants than causes of the improvement of Ach responsiveness seen after addition of diosgenin or fenugreek (Figure 3). It means that diosgenin (and possibly some other fenugreek components) was/were more potent in preserving the endothelium-dependent vasorelaxation during HFHSD than the endogenous antioxidant factors.

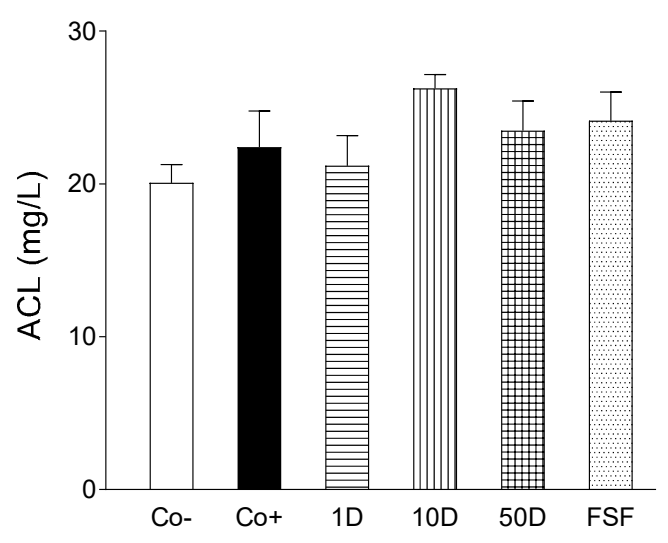

(a)

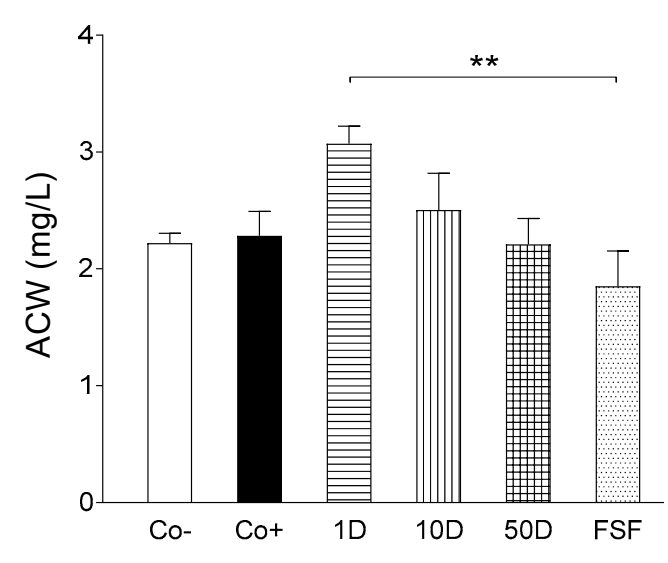

(b)

Figure 6. The effect of high-fat, high-sugar diet (HFHSD) (positive control: $\mathrm{Co}+$ ), $2 \mathrm{~g} / \mathrm{kg}$ bw/day fenugreek seed flour in addition to HFHSD (FSF), 1, 10 and $50 \mathrm{mg} / \mathrm{kg}$ bw/day diosgenin in addition to HFHSD (1D, 10D and 50D, respectively) on the antioxidant capacity of lipid- (ACL; (a)) and water-soluble (ACW; (b)) substances of blood in Wistar rats. The negative control group (Co-) consisted of rats receiving conventional rat food and tap water. The columns show the average values of the given groups (+SEM). Asterisks denote the significance level of differences between groups $(* *: p<0.01)$. 


\section{Discussion}

A primary outcome of the present study is that $2 \mathrm{~g} / \mathrm{kg}$ bw/day dietary fenugreek seed flour, and 10 and $50 \mathrm{mg} / \mathrm{kg}$ bw/day dietary diosgenin (all applied in addition to HFHSD) practically completely prevented ED produced by HFHSD alone. Furthermore, fenugreek seed flour appears to augment endothelium-dependent vasorelaxation at lower Ach levels than diosgenin, suggesting that components of fenugreek other than diosgenin might contribute to the beneficial effect of fenugreek seed flour. It has been also found that HFHSD alone markedly increased the plasma levels of both oxidized and reduced glutathione, while this treatment did not significantly affect the activity of either glutathione peroxidase or glutathione reductase. In contrast, both fenugreek and diosgenin caused a dramatic decrease in plasma levels of both oxidized and reduced glutathione, with a simultaneous remarkable attenuation of glutathione reductase (but not glutathione peroxidase) activity. Interestingly, the blood antioxidant capacity has been found relatively insensitive to the different feed regimens used in the present study, thus, underscoring the efficiency and flexibility (and relative resistance to dietary factors) of processes that maintain redox balance in the blood. These results suggest that antioxidant agents within fenugreek seed (especially diosgenin) can modify the regulatory pathways underlying the redox balance of the blood (in a complex manner) that may contribute to the beneficial effect of these compounds on endothelium-dependent arterial dilatory response under disrupted metabolic conditions. In addition, our results have confirmed the previous observation that ED is an early sign of disturbed carbohydrate and lipid metabolism. Moreover, our findings indicate that a decrease in the endothelium-dependent arterial relaxation caused by HFHSD can precede the manifest hyperglycemia and hyperinsulinemia.

$\mathrm{NO}$, a main vasodilatory substance, is generated through conversion of L-arginine to L-citrulline by three types of NO-synthases (NOSs): neuronal (nNOS or NOS1), inducible (iNOS or NOS2) and endothelial (eNOS or NOS3) ones. Endothelium expresses eNOS, while vascular smooth muscle was reported to contain all three NOS isoforms [27]. In the vascular smooth muscle cells, NO activates the guanylate cyclase causing an increase in cGMP level and consequent activation of protein kinase $G$ that induces vasorelaxation [28]. Beyond this classic effect, activating the protein kinase B (Act) pathway, NO exerts protective and regenerative effects on the endothelial cells, inhibits proliferation and migration of the smooth muscle cells [29-31]; thus, it acts as an anti-atherosclerotic agent-if it can reach its physiological targets in the arterial wall to induce its physiological effects. Namely, when the redox balance in the vascular wall shifts towards the oxidative direction, reactive oxygen species (ROS), e.g., superoxide anion $\left(\mathrm{O}_{2}{ }^{-}\right)$, transform $\mathrm{NO}$ into reactive nitrogen species (RNS) (in the case of $\mathrm{O}_{2}{ }^{-}$, into peroxynitrite) that results in nitrosative stress besides the oxidative one [32]. Although ROS are continuously generated even during the normal metabolism, ROS production, in response to all types of stress, shows a dramatic increase leading to the condition known as oxidative stress. Oxidative stress results in tissue damage and consequent inflammation, affecting a variety of metabolic pathways including NO homeostasis [33]. On one hand, expression of iNOS markedly increases followed by a substantial rise of $\mathrm{NO}$ (and $\mathrm{O}_{2}{ }^{-}$, see below) production. On the other hand, NOS isoforms (including eNOS) undergo a conformational change called uncoupling, as a result of which they will produce $\mathrm{O}_{2}{ }^{-}$instead of NO [34]. Paradoxically, in spite of the increased NO production in oxidative stress, deficiency of NO is seen at the level of the physiological NO-induced pathways, because of the enhanced NO consumption during RNS formation. The above-mentioned processes highlight the crucial role of redox status in the evolution of CVD [35].

Reduced glutathione (GSH) is the most significant small antioxidant molecule in living organisms, accomplishing the elimination of ROS and RNS, reduction of lipid peroxides, and protection of SHgroup containing enzymes from inactivation (via $S$-glutathionylation). During its reducing action, GSH turns into GSSG (oxidized glutathione (glutathione disulfide)), the oxidized form made through SH-bridge. GSH is transformed back in a NADPH-dependent reaction catalyzed by glutathione reductase, ensuring the redox balance in healthy organisms [36]. Deficiency of glutathione-related antioxidant defenses exists e.g., in atherosclerotic plaques [37]. 
Earlier studies have demonstrated that diosgenin influences the carbohydrate homeostasis at several molecular targets, being capable of effectively reducing hyperglycemia in pharmacologically induced rat diabetes models [38,39]. The underlying mechanisms are multifactorial and include restoration of pancreatic $\beta$-cell function, modulation of hepatic enzymes (regulating gluconeogenesis and antioxidant capacity of the liver) [40], promotion of adipocyte differentiation, inhibition of macrophage infiltration into adipose tissue, and decrease of expression of inflammatory genes [41]. It has been also observed that diosgenin decreases expression of the C/EBP homologous protein (CHOP) leading to reduced stress of endoplasmic reticulum in pancreatic islet $\beta$-cells. Moreover, diosgenin enhances expression of peroxisome proliferator-activated receptor gamma $(\mathrm{PPR} \gamma)$ that results in increased adipocyte differentiation, decreased adipocyte size and ectopic fat accumulation [38]. In addition, diosgenin, acting as a PPR $\gamma$ agonist, may mimic the effect of thiazolidinediones, classic insulin-sensitizing drugs, in the peripheral tissues [42].

Disturbance to lipid synthesis and accumulation is a characteristic phenomenon in obesity and MetS that promotes development of atherosclerosis and CVD. Thus, maintenance or restoration of normal lipid homeostasis is a major goal in the therapy of MetS [43,44]. Lipid metabolism is controlled by sterol-regulatory, element-binding proteins (SREBPs), a family of membrane-bound transcription factors. SREBPs activate expression of several genes associated with lipid absorption, excretion and metabolism [45]. SREBP-1c is influenced by liver $X$ receptor-a (LXRa), which functions primarily as a sterol sensor, with additional roles in bile acid synthesis and metabolism, cholesterol movement, fatty acid synthesis and lipoprotein metabolism [46]. It has been recently demonstrated that diosgenin can ameliorate dyslipidemia through inhibiting transactivation of LXRa in KK-Az mice [47]. This finding corroborates the observation that diosgenin increases levels of antioxidant and hepatoprotective enzymes in the blood plasma and liver, with concomitant improvement of $\beta$-cell regeneration and insulin secretion in streptozotocin-induced diabetic rats [40]. It has been also found that diosgenin increases the phosphorylation of AMP-activated protein kinase (AMPK) and acetyl-CoA carboxylase (ACC) in HepG2 cells, furthermore it suppresses LXRa in a rat model of non-alcoholic fatty liver disease (NAFLD), thus preventing development of NAFLD [48].

Ex vivo studies have revealed that diosgenin can directly modulate the function of arterial smooth muscle by regulating cell viability and blocking smooth muscle cell migration [49], furthermore it can evoke endothelium-dependent vasorelaxation that could be blocked by an eNOS inhibitor [50]. Moreover, in cultured human endothelial cells, diosgenin has been found to ameliorate FFA-induced endothelial dysfunction and insulin resistance via inhibiting the IKK $\beta$ and IRS-1 pathways [51].

Diosgenin is not the only phytochemical responsible for the beneficial effects of fenugreek. Fenugreek seed contains large amounts of amino acids, including 4-hydroxyisoleucine (4-OH-Ile) that stimulates insulin secretion and improves insulin sensitivity [52-55]. The underlying mechanism encompass enhancement of glucose uptake by translocation of GLUT4 (glucose transporter 4) to the plasma membrane [56]. Moreover, 4-OH-Ile also exerts anti-inflammatory action via reducing TNF- $\alpha$ mRNA expression [57,58]. Galactomannan, another component of fenugreek, inhibits some lipid- and carbohydrate-hydrolyzing enzymes, such as $\alpha$-glucosidase, that leads to decreased lipid and glucose absorption [59-61]. These properties of fenugreek compounds have been commercialized in products for general use, such as Fenfuro ${ }^{\mathrm{TM}}$, a patented dietary supplement containing fenugreek seed extract that has proven to be useful in the therapy of T2DM [62].

In association with the metabolic effects mentioned above, fenugreek seed and diosgenin both exhibit anti-inflammatory properties, the precise mechanism of which is not fully defined yet. Nevertheless, it has been observed that diosgenin inhibits expression of VCAM-1 (vascular cell adhesion molecule) and ICAM-1 (intracellular adhesion molecule), proteins involved in the pathogenesis of atherosclerosis, abolishes TNF- $\alpha$ induced production of intracellular ROS and inhibits NF- $\kappa B$ and I $\kappa B$ kinase activation, along with subsequent degradation of $I \kappa B \alpha$, and nuclear translocation of NF- $\mathrm{KB}$. These findings show that diosgenin is a potent agent for inhibiting the formation and growth of atherosclerotic lesions [24]. Decrease of ROS formation by diosgenin is especially important, because 
almost all ROS-related pathologic processes involve transformation of $\mathrm{NO}$ into peroxynitrite that conversion diminishes the bioavailability of $\mathrm{NO}$ and leads to the condition called ED [32].

Our finding, i.e., ED can be an early sign of metabolic diseases, is in agreement with results of several previous studies. In an investigation using rabbits fed with high-fat diet (HFD) for 2-8 weeks, ED developed already at the second week [63]. High level of free fatty acids (FFAs) thought to play a prominent role to evoke ED, because FFAs downregulate the AMPK/PI3K/Akt/eNOS signaling pathway [64], activate the NADPH oxidase leading to enhanced ROS generation and oxidative stress [65], and also activate the protein kinase C and NF-kB pathways hampering the vascular insulin signaling [66]. ED has been found to possess a prognostic impact on recognizing CVD [67], moreover it can be considered as an independent risk factor of CVD [68,69]. Consistently, in our early stage MetS model (with six-week HFHSD), ED developed even at normal plasma glucose and insulin levels.

According to the classic concept of the regulation of arterial tension, one of the most important roles of the endothelium is to respond to chemical stimuli such as Ach, by release of vasodilatory agents, notably NO, which acts on adjacent smooth muscle cells to relax and increase diameter of the blood vessel $[70,71]$. However, a new vasodilatory concept has recently been proposed which is that arterial smooth muscle is more than just a passive recipient of endothelial NO, and in fact it is a paracrine effector that responds to Ach by release of NO, thereby contributing to vascular tone regulation [72]. In this scenario, the role of the endothelial layer is predominantly to protect the arterial media from oxidative stressors (such as superoxide anion) and thereby to maintain the appropriate redox balance in the tissue compartment of arterial smooth muscle [27,73]. This concept is supported by the observation that presence of effective superoxide scavengers (tempol and $N$-acetyl-L-cysteine) allowed the endothelium-deprived rat aorta sections to partially preserve their dilatory response capacity to Ach. This observation suggests that the major underlying mechanism, by which endothelial cells enable the so-called endothelium-dependent vasorelaxation, is to protect the smooth muscle-derived NO from oxidative stressors and to allow it to mediate a dilatory action [72].

The precise mechanism of achieving a balance between vasoconstrictive and vasodilatory processes remains to be fully characterized. It nevertheless may be concluded that a complex relationship exists between endothelial function and redox conditions in the vasculature: the physiological endothelial function ensures the appropriate oxidoreductive state in the microenvironment of vascular smooth muscle (maintaining the intact smooth muscle responsiveness), while oxidative stress in the circulation damages the function of endothelial cells (shifting the redox balance in the media and thereby leading to weaker smooth muscle response to vasodilators). In this respect, results reported by the present study have provided further evidence in support of the significance of redox balance to sustain the normal dilatory susceptibility of arteries and thereby the physiological arterial tension. In addition, results of the present study demonstrate the significant antioxidant property of fenugreek seed compounds, especially that of diosgenin. Results of our functional assays indicate that dietary fenugreek seed flour as well as diosgenin (used in sufficiently high doses) can significantly improve, and indeed, practically restore the HFHSD-damaged arterial response to Ach, a classic vasodilatory signal molecule (Figure 3). Taking into consideration the functional findings reported here (Figure 3, Figure A1, Table A1) together with results of assays for blood redox status (Figures 4-6), it is proposed that improvement of endothelium-dependent vasorelaxation in response to fenugreek and diosgenin treatment was mediated by the antioxidant action of diosgenin and possibly by other fenugreek components. The above findings and interpretations, nevertheless, raise an important question: why is it that decreased antioxidant capacity was not detected in the plasma of animals receiving only HFHSD (positive controls), along with elevated plasma antioxidant capacity in the fenugreek- and diosgenin-treated animals, in comparison with the negative controls (Figure 6)? A speculative account for these observations is that the redox balance perturbed by HFHSD may be more easily compensated in the bloodstream than in the arterial media. An alternative (but not exclusive) explanation may be that in response to HFHSD, a special kind of redox balance developed in the blood. This redox state, 
although it seemed to be normal according to outcomes of the assays reported here, was insufficient to maintain physiological endothelial function and/or the intact smooth muscle responsiveness. In turn, scavengers of reactive oxygen species (such as diosgenin) could substantially increase the antioxidant capacity in the arterial wall without significantly affecting the redox balance in the blood, which may be due to their lipophilic property.

In summary, both fenugreek and diosgenin can prevent the impairment of arterial endothelial function (characterized by the response to Ach) developed during HFHSD. This beneficial effect may be associated with the simultaneous decrease in plasma glutathione levels and glutathione reductase activity that may reflect the reduced need for endogenous antioxidants in the presence of exogenous ones. Although patterns of beneficial effects of fenugreek and diosgenin are quite similar, they show some moderate differences. Namely, at lower Ach levels, fenugreek can produce somewhat stronger enhancement in the response to Ach than diosgenin. In light of the present results, fenugreek seed preparations may play an important role in future supplement therapy of metabolic disorders (including MetS), even at their early stage with seemingly intact body weight and carbohydrate homeostasis.

\section{Materials and Methods}

\subsection{Materials}

The following chemicals and preparations were used: conventional rat food (S8106-S011 SM R/M-Z + H, obtained from Ssniff Spezialdiäten GmbH, Soest, Germany), high-fat rat food (rodent maintenance (RM) Atwater fuel energy (AFE) $45 \%$ fat, $20 \%$ crude protein (CP) and 35\% carbohydrate $(\mathrm{CHO})$, obtained from Special Diets Services, Witham, UK), fenugreek seed flour (obtained from Trigonella Med. Ltd., Mosonmagyarovar, Hungary), norepinephrine hydrochloride (NE; obtained from the institutional drugstore as vial Arterenol ${ }^{\circledR}$, Sanofi-Aventis, Franfurt, Germany), furthermore diosgenin, acetylcholine chloride (Ach) and chemicals for Krebs solution (purchased from Sigma, St. Louis, MO, USA).

Krebs solution contained (in mmol/L): NaCl: 118, KCl: 4.7, CaCl2: 2.5, NaH2PO4: 1, MgCl2: 1.2, NaHCO3: 24.9, glucose: 11.5, and ascorbic acid: 0.1, dissolved in redistilled water. Krebs solution was used to dissolve Ach, and to dilute the NE solution.

\subsection{Animals and Protocols}

The investigation was approved by the Committee of Animal Research, University of Debrecen, Hungary (25/2013DEMÁB; date: 29 January 2014). Male Wistar rats weighting 300-500 g were randomly divided in six groups: negative control group receiving conventional rat food and tap water ad libitum $(n=6)$; positive control group receiving high-fat rat food and $5 \% \mathrm{~m} / v$ glucose solution ad libitum as high-fat, high-sugar diet (HFHSD) $(n=6)$; fenugreek group treated with $2 \mathrm{~g} / \mathrm{kg} \mathrm{bw} /$ day fenugreek seed flour (containing $10 \mathrm{mg} / \mathrm{kg}$ bw/day diosgenin) in addition to HFHSD $(n=9)$; diosgenin groups treated with 1,10 and $50 \mathrm{mg} / \mathrm{kg}$ bw/day diosgenin in addition to HFHSD ( $n=8,8$ and 8 , respectively). Fenugreek and diosgenin were added to the chow (at the beginning of the HFHSD treatment). The daily dose was calculated on the basis of average daily food consumption of the animals.

After 6 weeks, the animals were guillotined. Plasma glucose level was determined from the blood using Accu-Chek Active meter (Roche Holding AG, Basel, Switzerland). Plasma insulin was measured using ELISA kit (DA-INSULIN-2015; Cortez Diagnostics Inc., Woodland Hills, CA, USA). In addition, blood was collected from each rat into EDTA-coated vacutainer tubes (BD, Franklin Lakes, NJ, USA) to determine plasma concentrations of glutathione, glutathione-handling enzymes and antioxidant capacity. The blood samples were centrifuged at $1000 \times \mathrm{g}$ at $4{ }^{\circ} \mathrm{C}$ for $10 \mathrm{~min}$. The plasma was divided into aliquots and stored at $-20{ }^{\circ} \mathrm{C}$ until analysis. 


\subsection{Protocol of the Functional Assay}

Immediately after guillotining (and collecting blood), the proximal part of the abdominal aorta was isolated, and $2 \mathrm{~mm}$ wide rings were cut off (two rings from each animal). The rings were mounted horizontally at $10 \mathrm{mN}$ resting tension, using a wire instrument, in a 10-mL vertical organ chamber (Experimetria TSZ-04, Experimetria Ltd, Budapest, Hungary) containing Krebs solution, oxygenated with $95 \% \mathrm{O}_{2}$ and $5 \% \mathrm{CO}_{2}\left(36{ }^{\circ} \mathrm{C} ; \mathrm{pH}=7.4\right)$. The isometric contractile force of the circulatory muscle layer was measured by a transducer (Experimetria SD-01) and strain gauge (Experimetria SG-01D), and recorded by a polygraph (Medicor R-61 6CH Recorder).

After a 60-min incubation period, a NE concentration-response $(\mathrm{E} / \mathrm{c})$ curve (from $0.1 \mathrm{nmol} / \mathrm{L}$ to $1 \mu \mathrm{mol} / \mathrm{L}$ ) was generated on the aortic rings to determine their half maximal effective concentration $\left(\mathrm{EC}_{50}\right)$ value. After 60-min wash-out, $\mathrm{EC}_{50}$ for $\mathrm{NE}$ was administered to the rings, and, after the stabilization of the contractile force at a higher value (pre-contraction), an Ach E/c curve was constructed (from $0.1 \mathrm{nmol} / \mathrm{L}$ to $1 \mathrm{mmol} / \mathrm{L}$ ).

\subsection{Determination of Reduced (GSH) and Oxidized (GSSG) Glutathione}

GSH and GSSG were determined using a commercially available assay kit (kit number: 703002; Cayman Chemical, Ann Arbor, MI, USA). In the assay, 5,5'-dithio-bis (2-nitrobenzoic acid) (DTNB) and GSH react and generate a yellow product (2-nitro-5-thiobenzoic acid). Under the assay conditions, GSSG was reduced producing 2 molar equivalents of GSH. The absorbance was measured colorimetrically at $405 \mathrm{~nm}$ for both GSH and GSSG, and sample concentrations were determined by means of a standard GSH and GSSG curve expressing plasma concentrations in $\mu \mathrm{mol} / \mathrm{L}$ (respectively).

\subsection{Determination of Glutathione Peroxidase}

Glutathione peroxidase activity was determined using a commercially available assay kit (kit number: ab102530; Abcam Plc., Cambridge, UK). In this assay, glutathione peroxidase generates GSSG from GSH during $\mathrm{H}_{2} \mathrm{O}_{2}$ reduction and the generated GSSG is reduced back to GSH by glutathione reductase during consumption of NADPH. The reduction of NADPH is proportional to glutathione peroxidase activity, thus, it can be measured colorimetrically at $340 \mathrm{~nm}$. The kit reagents were dissolved as described in the protocol book. The standard curve was prepared as described in the kit. $90 \mu \mathrm{L}$ of diluted standard solutions was added into the correct wells. $50 \mu \mathrm{L}$ of samples, positive control and reagent control was added to the plate into the correct well. The reaction mixture was as described in the protocol book. The mix contained $33 \mu \mathrm{L}$ of assay buffer, $3 \mu \mathrm{L}$ of $40 \mathrm{mmol} / \mathrm{L}$ NADPH solution, $2 \mu \mathrm{L}$ of glutathione reductase solution and $2 \mu \mathrm{L}$ of GSH solution per well, except for standard wells. $40 \mu \mathrm{L}$ of the reaction mix was added to the samples, positive control and reagent control. The plate was incubated at room temperature for $15 \mathrm{~min}$. After incubation, absorbance was measured. If the absorbance value of the samples was lower than 1.0, then $1 \mu \mathrm{L}$ of $40 \mathrm{mmol} / \mathrm{L} \mathrm{NADPH}$ was added to the sample. $1 \mu \mathrm{L}$ of $40 \mathrm{mmol} / \mathrm{L}$ NADPH gave an $\sim 0.5$ increase in absorbance at $340 \mathrm{~nm}$. After this step, $10 \mu \mathrm{L}$ of cumene hydroperoxide was added to the samples, positive control and reagent control wells to start the glutathione peroxidase reaction. The microplate reader was set to take 1 reading every $5 \mathrm{~min}$ for $30 \mathrm{~min}$ for glutathione reductase activity measurement. Measurements started immediately after the addition of cumene hydroperoxide at $340 \mathrm{~nm}$ :

$$
\Delta A_{340 \mathrm{~nm}}=\left(\text { sample } A_{1}-\text { sample } A_{2}\right)-\left(\text { reagent control } A_{1}-\text { reagent control } A_{2}\right)
$$

where $A_{1}$ is the absorbance value in the first reading, $A_{2}$ is the absorbance data in the second reading. An NADPH standard curve was plotted and $\Delta A_{340 \mathrm{~nm}}$ was applied to this curve to obtain $\Delta B$ for NADPH. The obtained result was substituted into the equation:

$$
\text { glutathione peroxidase activity }=\frac{\Delta B}{\left(T_{2}-T_{1}\right) V} D
$$


where $\Delta B$ is the amount of NADPH that decreased between $T_{1}$ and $T_{2}$ (in nmol), $T_{1}$ is the time of the first reading $\left(A_{1}\right)(\mathrm{min}), T_{2}$ is the time of second reading $\left(A_{2}\right)(\mathrm{min}), V$ is the pre-treated sample volume added into the reaction well $(\mathrm{mL})$, and $D$ is the sample dilution factor. An NADPH standard curve was plotted, and equations suggested by the kit were used. The activity of glutathione peroxidase was expressed in $\mathrm{nmol} / \mathrm{min} / \mathrm{mL}=\mathrm{U} / \mathrm{L}$.

\subsection{Determination of Glutathione Reductase}

Glutathione reductase activity was determined using a commercially available assay kit (kit number: ab83461; Abcam Plc., Cambridge, UK). In this assay, glutathione reductase forms GSH from GSSG, then, while GSH reacts with DTNB, a 2-nitro-5-thiobenzoate anion $\left(\mathrm{TNB}^{2-}\right)$ is generated. By measuring the change in absorbance at $405 \mathrm{~nm}$, glutathione reductase activity can be determined as follows:

$$
\text { glutathione reductase activity }=\frac{\Delta B}{\left(T_{2}-T_{1}\right) 0.9 \mathrm{~V}} D
$$

where $\Delta B$ is the TNB amount from TNB standard curve (in nmol), $T_{1}$ is the time of the first reading $\left(A_{1}\right)$ (in $\mathrm{min}$ ), $T_{2}$ is the time of the second reading $\left(A_{2}\right)$ (in $\mathrm{min}$ ), $V$ is the pre-treated sample volume added into the reaction well (in $\mathrm{mL}$ ), 0.9 is the sample volume change factor during the sample pre-treatment procedure, and $D$ is the dilution factor, as suggested in the kit's description. Glutathione reductase activity was expressed in $\mathrm{nmol} / \mathrm{min} / \mathrm{mL}=\mathrm{U} / \mathrm{L}$.

\subsection{Determination of Antioxidant Capacity of Water-Soluble Compounds (ACW)}

ACW was determined using a commercially available ACW kit (kit number: 846-60002-0; Analytik Jena AG, Jena, Germany). Radicals were generated photochemically by UV irradiation of a photosensitizer compound. PhotoChem measures the inhibition of radicals by the sample ACW content. The ACW kit contains R1, R2, R3 and R4 reagents. R1 and R2 are ready for use and stored at $2-8{ }^{\circ} \mathrm{C}$. R3 is lyophilized and stored at $-20^{\circ} \mathrm{C}$ until use. $750 \mu \mathrm{L}$ of $\mathrm{R} 2$ reagent was added into R3 and was ready to use. A stock solution was made from R4 reagent, $490 \mu \mathrm{L}$ of R1 reagent and $10 \mu \mathrm{L}$ of $\mathrm{H}_{2} \mathrm{SO}_{4}$ were added into R4 reagent. 10-fold dilutions were made from the stock solution $(10 \mu \mathrm{L}$ of $\mathrm{R} 4$ stock solution $+990 \mu \mathrm{L}$ of R1 solution). First the blank was prepared: $1500 \mu \mathrm{L}$ of R1, $1000 \mu \mathrm{L}$ of $\mathrm{R} 2$, and $25 \mu \mathrm{L}$ of $\mathrm{R} 3$ were mixed. A calibration was made between 0.1 and $2 \mathrm{nmol}$ (at least 5 points) with L-ascorbic acid standard. The plasma sample was centrifuged at 10,000 rpm for $5 \mathrm{~min}$ and the supernatant of samples was used for measurements. The working solution contained $1490 \mu \mathrm{L}$ of R1, $1000 \mu \mathrm{L}$ of $\mathrm{R} 2,25 \mu \mathrm{L}$ of $\mathrm{R} 3$ and $10 \mu \mathrm{L}$ of samples. The calculation for the lyophilized sample is:

$$
\text { concentration }=\frac{(\text { results })(\text { dilution })(176.13)}{\text { pipetted volume }}
$$

The "result" is the result by the PhotoChem, 176.13 is the molecular weight of L-ascorbic acid, pipetted volume is the sample volume (in $\mu \mathrm{L}$ ). The final result was expressed as $\mu \mathrm{g} / \mathrm{mL} \mathrm{L}$-ascorbic acid equivalent.

\subsection{Determination of Antioxidant Capacity of Lipid-Soluble Compounds (ACL)}

ACL was determined using a commercially available ACL kit (kit number: 849-60004-0; Analytikjena AG). The method is similar to that used for ACW test. The ACL kit contain R1, R2, $\mathrm{R} 3$, and $\mathrm{R} 4$ reagents. $\mathrm{R} 1$ and $\mathrm{R} 2$ were ready for use but stored at $2-8{ }^{\circ} \mathrm{C}$. R3 was lyophilized and stored at $-20^{\circ} \mathrm{C}$ until use. $750 \mu \mathrm{L}$ of $\mathrm{R} 2$ reagent was added into $\mathrm{R} 3$ and was ready to use. Stock solution was made from R4 reagent: $500 \mu \mathrm{L}$ of R1 reagent was added into R4 reagent, and 10-fold dilutions were prepared from the stock solution $(10 \mu \mathrm{L}$ of $\mathrm{R} 4$ stock solution $+990 \mu \mathrm{L}$ of $\mathrm{R} 1$ solution. First the blank was prepared: $2300 \mu \mathrm{L}$ of R1, $200 \mu \mathrm{L}$ of R2, and $25 \mu \mathrm{L}$ of R3 were mixed. A calibration was made between $0.2 \mathrm{nmol}$ and $3 \mathrm{nmol}$ (at least 5 points) with a trolox standard. The sample was centrifuged at 
$10,000 \times g$ for $5 \mathrm{~min}$. The supernatant of prepared samples was use for measurements. The working solution contained $2290 \mu \mathrm{L}$ of R1, $200 \mu \mathrm{L}$ of $\mathrm{R} 2,25 \mu \mathrm{L}$ of $\mathrm{R} 3$ and $10 \mu \mathrm{L}$ of the samples. The calculation for the lyophilized sample is:

$$
\text { concentration }=\frac{(\text { results })(\text { dilution })(250.3)}{\text { pipetted volume }}
$$

The "result" means the result by the PhotoChem, 250.3 is the molecular weight of trolox, pipetted volume is the sample volume (in $\mu \mathrm{L}$ ). The final result was expressed as $\mu \mathrm{g} / \mathrm{mL}$ trolox equivalent.

\subsection{Data Processing and Analysis}

Responses of aortic rings obtained from the same rat were averaged.

The effect of NE was defined as an (absolute) increase in addition to the resting tension $(10 \mathrm{mN})$ of aortic rings.

If relaxation occurred in the presence of a given Ach concentration, the maximal relaxation was considered. If the ring produced a contraction, its maximum was taken into account. The effect of Ach was defined as a percentage change in the initial tension of aortic rings (after the pre-contraction with $\mathrm{NE}$ using their $\mathrm{EC}_{50}$ value).

Normality of data sets was verified with D'Agostino-Pearson omnibus test. Two data sets were compared with unpaired, two-tailed Student's $t$ test or Welch's $t$ test (if variances were not equal). More than two data sets were compared using one-way ANOVA (with Geisser-Greenhouse correction) followed by Tukey post-testing. Difference of means was considered significant at $p<0.05$. Statistical analysis was carried out with GraphPad Prism 7.04 (GraphPad Software Inc., La Jolla, CA, USA).

Acknowledgments: The work/publication is supported by the GINOP-2.3.2-15-2016-00062 project. The project is co-financed by the European Union and the European Regional Development Fund. This work was also supported in part by AGR-PIAC-13-1-2013-0008. The authors are sincerely grateful to Stephanie C. Fox, of QueenBeeEdit in Bloomfield, CT, USA, for her hard work in organizing, formatting, and editing this article.

Author Contributions: Katalin Szabó: functional assay with aortic rings, preparation of the first draft of the manuscript; Rudolf Gesztelyi: functional assay with aortic rings, statistical analysis; Nóra Lampé: functional assay with aortic rings; Rita Kiss: treatment of the animals, sample preparation, data handling; Judit Remenyik and Georgina Pesti-Asbóth: glutathione and enzyme activity measurements, antioxidant capacity assays; Dániel Priksz: animal treatment, contribution to the manuscript preparation; Zoltán Szilvássy and Béla Juhász: study design, finalization of the manuscript.

Conflicts of Interest: The authors declare no conflict of interest.

$\begin{array}{ll}\text { Abbreviations } & \\ \text { 4-OH-Ile } & \text { 4-hydroxyisoleucine } \\ \text { ACC } & \text { acetyl-CoA carboxylase } \\ \text { Ach } & \text { acetylcholine } \\ \text { ACL } & \text { lipid soluble antioxidant capacity } \\ \text { Act } & \text { protein kinase B (PKB) } \\ \text { AMPK } & \text { adenosine monophosphate-activated protein kinase } \\ \text { AWS } & \text { water soluble antioxidant capacity } \\ \text { bw } & \text { body weight } \\ \text { cGMP } & \text { cyclic guanosine monophosphate } \\ \text { CHOP } & \text { CCAAT-enhancer-binding homologous protein } \\ \text { CVD } & \text { cardiovascular diseases } \\ \text { ED } & \text { endothelial dysfunction } \\ \text { eNOS } & \text { endothelial nitric oxide synthase } \\ \text { FFA } & \text { free fatty acid } \\ \text { GLUT4 } & \text { glucose transporter 4 } \\ \text { GSH } & \text { reduced glutathione (glutathione) } \\ \text { GSSG } & \text { oxidized glutathione (glutathione disulfide) }\end{array}$




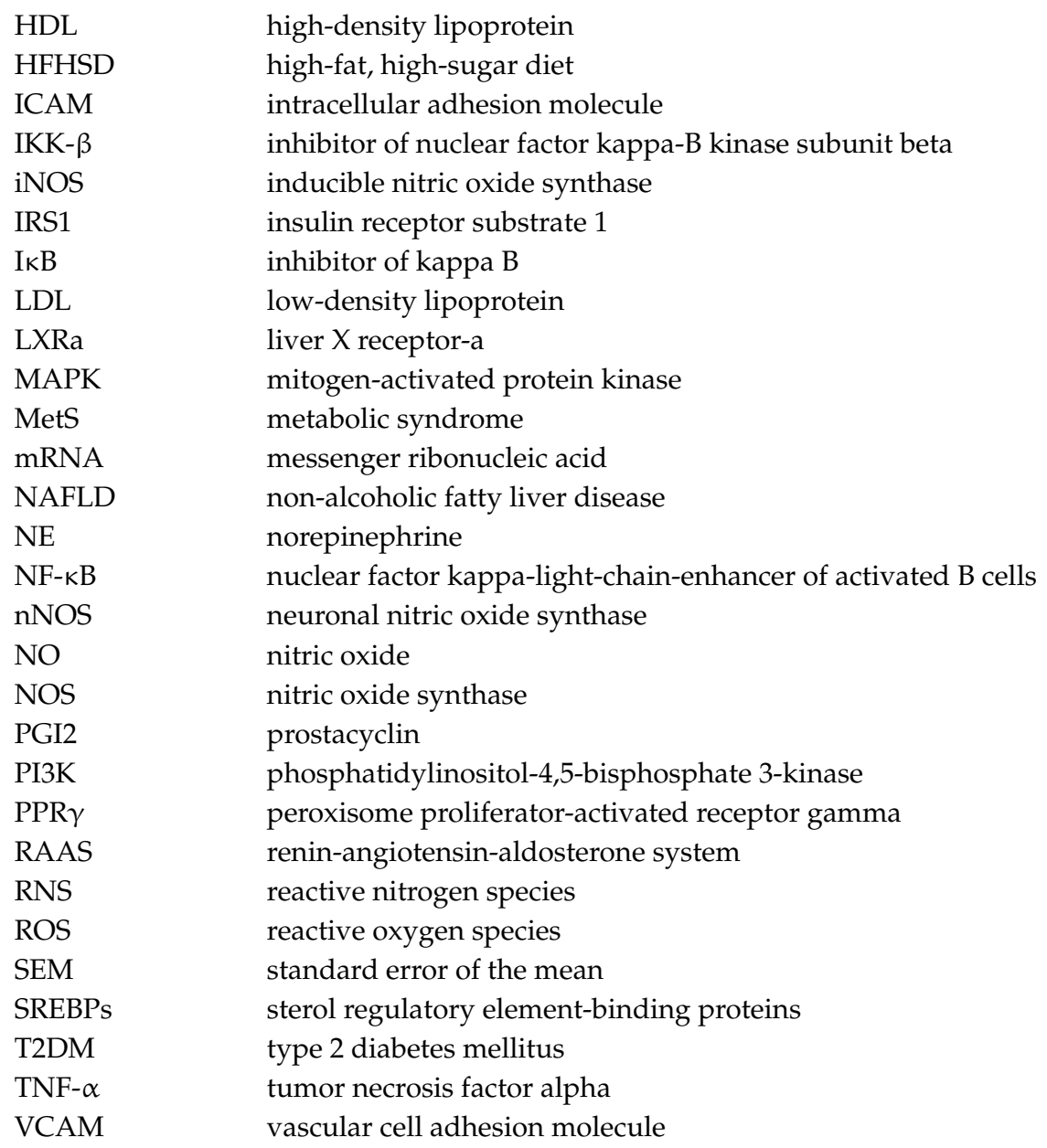

\section{Appendix A}

For the evaluation of an E/c curve, nonlinear regression (curve fitting) is a common method [74]. However, Ach E/c curves of the present investigation, in their original form, were not suitable for curve fitting, because two opposite responses were evoked by Ach: a relaxation mediated by NO (synthesized in the endothelial and perhaps arterial smooth muscle cells), and an NO-independent contraction. Although, due to its greater $\mathrm{EC}_{50}$ value, this latter effect developed with a considerable delay along the axis $x$, there was a significant overlap between the two opposite responses (as a resultant, see Figure 3) that hindered the reliable fitting of the Hill equation, the most common choice to assess an E/c relationship [75].

In order to quantify separately the NO-dependent relaxation and to make the regression more reliable, Ach E/c data cleansing and manipulation were performed as follows. For each individual Ach $\mathrm{E} / \mathrm{c}$ curve (resulted from averaging of data of the two aortic rings obtained from the same animal), the maximal effect value was chosen and arbitrarily assigned to all Ach concentrations that were higher than the Ach concentration, to which the maximal effect belonged. Furthermore, zero effect was assigned to three surely effectless Ach concentration values (1, 10, $100 \mathrm{fmol} / \mathrm{L})$, and these $\mathrm{E} / \mathrm{c}$ data were arbitrarily added to each individual Ach E/c data set. These modified Ach E/c curves were fitted to the Hill equation (in the GraphPad Prism software, the four-parameter log[agonist] vs. response equation with a bottom constrained to zero).

The fenugreek- and diosgenin-treated aortic rings produced practically the same Ach-induced arterial relaxation as the negative control aortic rings (representing the healthy state), and they all showed more pronounced dilatory response to Ach than the positive control preparations (reflecting the ED in an early-stage MetS) (Figure A1). 


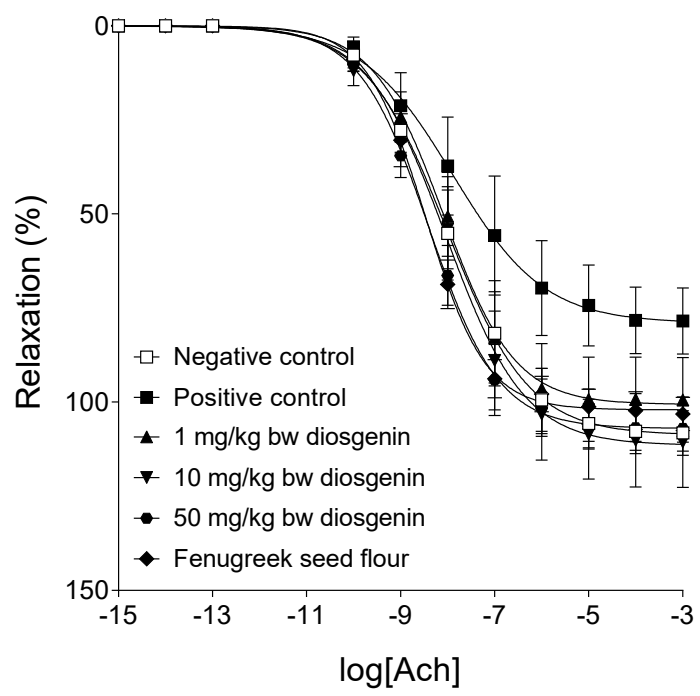

Figure A1. The relationship between the concentration of acetylcholine (Ach) and the NO-mediated (so-called endothelium-dependent) arterial relaxation in experimental groups subjected to different diets, created from real Ach concentration-response (E/c) curves presented on Figure 3. The axis $x$ shows the common logarithm of molar concentration of Ach, and the axis $y$ indicates the effect as a percentage decrease of the initial contractile force. The symbols show the modified effect values averaged within the groups $( \pm \mathrm{SEM})$, and the lines denote the Hill equation fitted to the averaged modified Ach E/c data.

The $\mathrm{E}_{\max }, \log \mathrm{EC}_{50}$ and $\mathrm{n}$ (Hill coefficient) parameters provided by the Hill equation (fitted to the individual modified Ach E/c data) were compared among the different experimental groups. Only differences of $E_{\max }$ values reached the level of statistical significance: $E_{\max }$ of the negative control group, $50 \mathrm{mg}$ diosgenin group and fenugreek group significantly exceeded that of the positive control group (receiving HFHSD) (Table A1), in agreement with the results of analysis of real Ach E/c curves (Figure 3). Additionally, ED in the positive control group reflected in a moderately increased $\mathrm{EC}_{50}$, while beneficial effect of diosgenin and fenugreek prevented the deleterious action of HFHSD. Moreover, treatments with the highest diosgenin dose and fenugreek decreased $\mathrm{EC}_{50}$ even as compared to the negative control. The Hill coefficient values of the groups varied between 0.64 and 0.73 , excepting the fenugreek group, in which it increased to 0.85 (maybe as a results of the complex effect of different fenugreek components on the signaling pathways of Ach in the arterial wall) (Table A1). Our results yielded by curve fitting corroborate the findings obtained from the comparison of effect values of the intact Ach E/c curves (Figure 3).

Table A1. Regression parameters (expressed in mean \pm SEM) of the Hill equation fitted to the individual modified acetylcholine (Ach) concentration-response (E/c) curves. Level of statistical significance for differences between the positive vs. negative control groups (asterisk), and between the diosgenin and fenugreek treated groups vs. positive control group (hash mark) is indicated $\left({ }^{*}, \#: p<0.05\right)$.

\begin{tabular}{ccccccc}
\hline & Co- & Co+ & 1D & 10D & 50D & FSF \\
\hline $\mathrm{E}_{\max }$ & $108.11 \pm 6.05$ & $79.66 \pm 8.6^{*}$ & $100.58 \pm 11.31$ & $111.12 \pm 11.9$ & $107.80 \pm 5.56 \#$ & $101.84 \pm 4.43 \#$ \\
$\log \mathrm{C}_{50}$ & $-7.94 \pm 0.32$ & $-7.65 \pm 0.54$ & $-7.95 \pm 0.25$ & $-7.95 \pm 0.23$ & $-8.3 \pm 0.23$ & $-8.45 \pm 0.14$ \\
$n$ & $0.67 \pm 0.07$ & $0.68 \pm 0.07$ & $0.73 \pm 0.08$ & $0.65 \pm 0.07$ & $0.64 \pm 0.04$ & $0.85 \pm 0.1$ \\
\hline
\end{tabular}

Co-: negative control group (receiving commercial rat diet); $\mathrm{Co}+$ : positive control group (receiving high-fat, high-sugar diet (HFHSD)); 1D, 10D and 50D: groups treated with 1, 10 and $50 \mathrm{mg} / \mathrm{kg}$ bw/day diosgenin in addition to HFHSD, respectively; FSF: group treated with $2 \mathrm{~g} / \mathrm{kg}$ bw $/$ day fenugreek seed flour (containing $10 \mathrm{mg} / \mathrm{kg}$ bw/day diosgenin); $\mathrm{E}_{\max }$ : maximal effect; $\log \mathrm{EC}_{50}$ : common logarithm of $\mathrm{EC}_{50}$, the concentration producing half-maximal effect; $n$ : Hill coefficient (slope factor). 


\section{References}

1. Grundy, S.M.; Cleeman, J.I.; Daniels, S.R.; Donato, K.A.; Eckel, R.H.; Franklin, B.A.; Gordon, D.J.; Krauss, R.M.; Savage, P.J.; Smith, S.C., Jr.; et al. Diagnosis and management of the metabolic syndrome: An American Heart Association/National Heart, Lung, and Blood Institute Scientific Statement. Circulation 2005, 112, 2735-2752. [CrossRef] [PubMed]

2. Alberti, K.G.; Zimmet, P.; Shaw, J.; IDF Epidemiology Task Force Consensus Group. The metabolic syndrome-A new worldwide definition. Lancet 2005, 366, 1059-1062. [CrossRef]

3. Alberti, K.G.; Eckel, R.H.; Grundy, S.M.; Zimmet, P.Z.; Cleeman, J.I.; Donato, K.A.; Fruchart, J.C.; James, W.P.; Loria, C.M.; Smith, S.C., Jr.; et al. Harmonizing the metabolic syndrome: A joint interim statement of the International Diabetes Federation Task Force on Epidemiology and Prevention; National Heart, Lung, and Blood Institute; American Heart Association; World Heart Federation; International Atherosclerosis Society; and International Association for the Study of Obesity. Circulation 2009, 120, 1640-1645. [PubMed]

4. Klein, B.E.; Klein, R.; Lee, K.E. Components of the metabolic syndrome and risk of cardiovascular disease and diabetes in Beaver Dam. Diabetes Care 2002, 25, 1790-1794. [CrossRef] [PubMed]

5. Schachinger, V.; Zeiher, A.M. Atherosclerosis-associated endothelial dysfunction. Z. Kardiol. 2000, 89 (Suppl. 9), IX70-IX74. [CrossRef]

6. Beckman, J.A.; Creager, M.A.; Libby, P. Diabetes and atherosclerosis: Epidemiology, pathophysiology, and management. JAMA 2002, 287, 2570-2581. [CrossRef] [PubMed]

7. Vane, J.R.; Anggard, E.E.; Botting, R.M. Regulatory functions of the vascular endothelium. N. Engl. J. Med. 1990, 323, 27-36. [PubMed]

8. Meyers, M.R.; Gokce, N. Endothelial dysfunction in obesity: Etiological role in atherosclerosis. Curr. Opin. Endocrinol. Diabetes Obes. 2007, 14, 365-369. [CrossRef] [PubMed]

9. Polovina, M.M.; Potpara, T.S. Endothelial dysfunction in metabolic and vascular disorders. Postgrad. Med. 2014, 126, 38-53. [CrossRef] [PubMed]

10. Félétou, M. The endothelium, Part I: Multiple functions of the endothelial cells-Focus on endothelium-derived vasoactive mediators. in Colloquium Series on Integrated Systems Physiology: From Molecule to Function. Morgan Claypool Life Sci. 2011, 3, 306.

11. Dharmashankar, K.; Widlansky, M.E. Vascular endothelial function and hypertension: Insights and directions. Curr. Hypertens. Rep. 2010, 12, 448-455. [CrossRef] [PubMed]

12. Konukoglu, D.; Uzun, H. Endothelial Dysfunction and Hypertension. Adv. Exp. Med. Biol 2017, 956, 511-540. [PubMed]

13. Deedwania, P.C. Mechanisms of endothelial dysfunction in the metabolic syndrome. Curr. Diabetes Rep. 2003, 3, 289-292. [CrossRef]

14. Hsueh, W.A.; Lyon, C.J.; Quinones, M.J. Insulin resistance and the endothelium. Am. J. Med. 2004, 117, 109-117. [CrossRef] [PubMed]

15. Fuller, S.; Stephens, J.M. Diosgenin, 4-hydroxyisoleucine, and fiber from fenugreek: Mechanisms of actions and potential effects on metabolic syndrome. Adv. Nutr. 2015, 6, 189-197. [CrossRef] [PubMed]

16. Mahdavi, M.R.; Roghani, M.; Baluchnejadmojarad, T. Mechanisms responsible for the vascular effect of aqueous Trigonella foenum-graecum leaf extract in diabetic rats. Indian J. Pharmacol. 2008, 40, 59-63. [PubMed]

17. Vaez Mahdavi, M.R.; Roghani, M.; Baluchnejadmojarad, T. The Role of Adrenergic and Angiotensinergic Systems in Vascular Effect of Alcoholic of Extract Trigonella foenum-graecum Seed in Diabetic Rats. Iran. J. Pharm. Res. 2011, 10, 83-88. [PubMed]

18. Chen, Y.; Xu, X.; Zhang, Y.; Liu, K.; Huang, F.; Liu, B.; Kou, J. Diosgenin regulates adipokine expression in perivascular adipose tissue and ameliorates endothelial dysfunction via regulation of AMPK. J. Steroid Biochem. Mol. Biol. 2016, 155 Pt A, 155-165. [CrossRef] [PubMed]

19. Manivannan, J.; Balamurugan, E.; Silambarasan, T.; Raja, B. Diosgenin improves vascular function by increasing aortic eNOS expression, normalize dyslipidemia and ACE activity in chronic renal failure rats. Mol. Cell. Biochem. 2013, 384, 113-120. [CrossRef] [PubMed]

20. Manivannan, J.; Barathkumar, T.R.; Sivasubramanian, J.; Arunagiri, P.; Raja, B.; Balamurugan, E. Diosgenin attenuates vascular calcification in chronic renal failure rats. Mol. Cell. Biochem. 2013, 378, 9-18. [CrossRef] [PubMed] 
21. Pari, L.; Monisha, P.; Mohamed Jalaludeen, A. Beneficial role of diosgenin on oxidative stress in aorta of streptozotocin induced diabetic rats. Eur. J. Pharmacol. 2012, 691, 143-150. [CrossRef] [PubMed]

22. Manivannan, J.; Shanthakumar, J.; Arunagiri, P.; Raja, B.; Balamurugan, E. Diosgenin interferes coronary vasoconstriction and inhibits osteochondrogenic transdifferentiation of aortic VSMC in CRF rats. Biochimie 2014, 102, 183-187. [CrossRef] [PubMed]

23. Roghani-Dehkordi, F.; Roghani, M.; Baluchnejadmojarad, T. Diosgenin Mitigates Streptozotocin Diabetes-induced Vascular Dysfunction of the Rat Aorta: The Involved Mechanisms. J. Cardiovasc. Pharmacol. 2015, 66, 584-592. [CrossRef] [PubMed]

24. Choi, K.W.; Park, H.J.; Jung, D.H.; Kim, T.W.; Park, Y.M.; Kim, B.O.; Sohn, E.H.; Moon, E.Y.; Um, S.H.; Rhee, D.K.; et al. Inhibition of TNF-alpha-induced adhesion molecule expression by diosgenin in mouse vascular smooth muscle cells via downregulation of the MAPK, Akt and NF-kappaB signaling pathways. Vasc. Pharmacol. 2010, 53, 273-280. [CrossRef] [PubMed]

25. Marques, C.; Meireles, M.; Norberto, S.; Leite, J.; Freitas, J.; Pestana, D.; Faria, A.; Calhau, C. High-fat diet-induced obesity Rat model: A comparison between Wistar and Sprague-Dawley Rat. Adipocyte 2016, 5 , 11-21. [CrossRef] [PubMed]

26. Wang, Y.; Wang, P.Y.; Qin, L.Q.; Davaasambuu, G.; Kaneko, T.; Xu, J.; Murata, S.; Katoh, R.; Sato, A. The development of diabetes mellitus in Wistar rats kept on a high-fat/low-carbohydrate diet for long periods. Endocrine 2003, 22, 85-92. [CrossRef]

27. Buchwalow, I.B.; Podzuweit, T.; Samoilova, V.E.; Wellner, M.; Haller, H.; Grote, S.; Aleth, S.; Boecker, W.; Schmitz, W.; Neumann, J. An in situ evidence for autocrine function of NO in the vasculature. Nitric Oxide 2004, 10, 203-212. [CrossRef] [PubMed]

28. Denninger, J.W.; Marletta, M.A. Guanylate cyclase and the .NO/cGMP signaling pathway. Biochim. Biophys. Acta 1999, 1411, 334-350. [CrossRef]

29. Fukumura, D.; Gohongi, T.; Kadambi, A.; Izumi, Y.; Ang, J.; Yun, C.O.; Buerk, D.G.; Huang, P.L.; Jain, R.K. Predominant role of endothelial nitric oxide synthase in vascular endothelial growth factor-induced angiogenesis and vascular permeability. Proc. Natl. Acad. Sci. USA 2001, 98, 2604-2609. [CrossRef] [PubMed]

30. Lei, J.; Vodovotz, Y.; Tzeng, E.; Billiar, T.R. Nitric oxide, a protective molecule in the cardiovascular system. Nitric Oxide 2013, 35, 175-185. [CrossRef] [PubMed]

31. Guber, S.; Ebrahimian, T.; Heidari, M.; Eliopoulos, N.; Lehoux, S. Endothelial nitric oxide synthase overexpressing human early outgrowth cells inhibit coronary artery smooth muscle cell migration through paracrine functions. Sci. Rep. 2018, 8, 877. [CrossRef] [PubMed]

32. Lubos, E.; Handy, D.E.; Loscalzo, J. Role of oxidative stress and nitric oxide in atherothrombosis. Front. Biosci. 2008, 13, 5323-5344. [CrossRef] [PubMed]

33. Roe, N.D.; Ren, J. Nitric oxide synthase uncoupling: A therapeutic target in cardiovascular diseases. Vasc. Pharmacol. 2012, 57, 168-172. [CrossRef] [PubMed]

34. Luo, S.; Lei, H.; Qin, H.; Xia, Y. Molecular mechanisms of endothelial NO synthase uncoupling. Curr. Pharm. Design 2014, 20, 3548-3553. [CrossRef]

35. Karbach, S.; Wenzel, P.; Waisman, A.; Munzel, T.; Daiber, A. eNOS uncoupling in cardiovascular diseases-the role of oxidative stress and inflammation. Curr. Pharm. Design 2014, 20, 3579-3594. [CrossRef]

36. Dalle-Donne, I.; Rossi, R.; Colombo, G.; Giustarini, D.; Milzani, A. Protein S-glutathionylation: A regulatory device from bacteria to humans. Trends Biochem. Sci. 2009, 34, 85-96. [CrossRef] [PubMed]

37. Lapenna, D.; de Gioia, S.; Ciofani, G.; Mezzetti, A.; Ucchino, S.; Calafiore, A.M.; Napolitano, A.M.; Di Ilio, C.; Cuccurullo, F. Glutathione-related antioxidant defenses in human atherosclerotic plaques. Circulation 1998, 97, 1930-1934. [CrossRef] [PubMed]

38. Tharaheswari, M.; Jayachandra Reddy, N.; Kumar, R.; Varshney, K.C.; Kannan, M.; Sudha Rani, S. Trigonelline and diosgenin attenuate ER stress, oxidative stress-mediated damage in pancreas and enhance adipose tissue PPARgamma activity in type 2 diabetic rats. Mol. Cell. Biochem. 2014, 396, 161-174. [CrossRef] [PubMed]

39. Saravanan, G.; Ponmurugan, P.; Deepa, M.A.; Senthilkumar, B. Modulatory effects of diosgenin on attenuating the key enzymes activities of carbohydrate metabolism and glycogen content in streptozotocin-induced diabetic rats. Can. J. Diabetes 2014, 38, 409-414. [CrossRef] [PubMed] 
40. Kalailingam, P.; Kannaian, B.; Tamilmani, E.; Kaliaperumal, R. Efficacy of natural diosgenin on cardiovascular risk, insulin secretion, and beta cells in streptozotocin (STZ)-induced diabetic rats. Phytomedicine 2014, 21, 1154-1161. [CrossRef] [PubMed]

41. Uemura, T.; Hirai, S.; Mizoguchi, N.; Goto, T.; Lee, J.Y.; Taketani, K.; Nakano, Y.; Shono, J.; Hoshino, S.; Tsuge, N.; et al. Diosgenin present in fenugreek improves glucose metabolism by promoting adipocyte differentiation and inhibiting inflammation in adipose tissues. Mol. Nutr. Food Res. 2010, 54, 1596-1608. [CrossRef] [PubMed]

42. Sangeetha, M.K.; ShriShri Mal, N.; Atmaja, K.; Sali, V.K.; Vasanthi, H.R. PPAR's and Diosgenin a chemico biological insight in NIDDM. Chem. Biol. Interact. 2013, 206, 403-410. [CrossRef] [PubMed]

43. Lim, S.; Meigs, J.B. Ectopic fat and cardiometabolic and vascular risk. Int. J. Cardiol. 2013, 169, $166-176$. [CrossRef] [PubMed]

44. Morelli, M.; Gaggini, M.; Daniele, G.; Marraccini, P.; Sicari, R.; Gastaldelli, A. Ectopic fat: The true culprit linking obesity and cardiovascular disease? Thromb. Haemost. 2013, 110, 651-660. [CrossRef] [PubMed]

45. Horton, J.D.; Goldstein, J.L.; Brown, M.S. SREBPs: Activators of the complete program of cholesterol and fatty acid synthesis in the liver. J. Clin. Investig. 2002, 109, 1125-1131. [CrossRef] [PubMed]

46. Edwards, P.A.; Kast, H.R. Anisfeld, A.M. BAREing it all: The adoption of LXR and FXR and their roles in lipid homeostasis. J. Lipid Res. 2002, 43, 2-12. [PubMed]

47. Uemura, T.; Goto, T.; Kang, M.S.; Mizoguchi, N.; Hirai, S.; Lee, J.Y.; Nakano, Y.; Shono, J.; Hoshino, S.; Taketani, K.; et al. Diosgenin, the main aglycon of fenugreek, inhibits LXRalpha activity in HepG2 cells and decreases plasma and hepatic triglycerides in obese diabetic mice. J. Nutr. 2011, 141, 17-23. [CrossRef] [PubMed]

48. Cheng, S.; Liang, S.; Liu, Q.; Deng, Z.; Zhang, Y.; Du, J.; Zhang, Y.; Li, S.; Cheng, B.; Ling, C. Diosgenin prevents high-fat diet-induced rat non-alcoholic fatty liver disease through the AMPK and LXR signaling pathways. Int. J. Mol. Med. 2018, 41, 1089-1095. [CrossRef] [PubMed]

49. Esfandiarei, M.; Lam, J.T.; Yazdi, S.A.; Kariminia, A.; Dorado, J.N.; Kuzeljevic, B.; Syyong, H.T.; Hu, K.; van Breemen, C. Diosgenin Modulates Vascular Smooth Muscle Cell. Function by Regulating Cell. Viability, Migration, and Calcium Homeostasis. J. Pharmacol. Exp. Ther. 2011, 336, 925-939. [CrossRef] [PubMed]

50. Dias, K.L.; Correia Nde, A.; Pereira, K.K.; Barbosa-Filho, J.M.; Cavalcante, K.V.; Araújo, I.G.; Silva, D.F.; Guedes, D.N.; Neto Mdos, A.; Bendhack, L.M.; et al. Mechanisms involved in the vasodilator effect induced by diosgenin in rat superior mesenteric artery. Eur. J. Pharmacol. 2007, 574, 172-178. [CrossRef] [PubMed]

51. Liu, K.; Zhao, W.; Gao, X.; Huang, F.; Kou, J.; Liu, B. Diosgenin ameliorates palmitate-induced endothelial dysfunction and insulin resistance via blocking IKK $\beta$ and IRS-1 pathways. Atherosclerosis 2012, 223, 350-358. [CrossRef] [PubMed]

52. Sauvaire, Y.; Petit, P.; Broca, C.; Manteghetti, M.; Baissac, Y.; Fernandez-Alvarez, J.; Gross, R.; Roye, M.; Leconte, A.; Gomis, R.; et al. 4-Hydroxyisoleucine: A novel amino acid potentiator of insulin secretion. Diabetes 1998, 47, 206-210. [CrossRef] [PubMed]

53. Broca, C.; Gross, R.; Petit, P.; Sauvaire, Y.; Manteghetti, M.; Tournier, M.; Masiello, P.; Gomis, R.; Ribes, G. 4-Hydroxyisoleucine: Experimental evidence of its insulinotropic and antidiabetic properties. Am. J. Physiol. 1999, 277 Pt 1, E617-E623. [CrossRef] [PubMed]

54. Broca, C.; Manteghetti, M.; Gross, R.; Baissac, Y.; Jacob, M.; Petit, P.; Sauvaire, Y.; Ribes, G. 4-Hydroxyisoleucine: Effects of synthetic and natural analogues on insulin secretion. Eur. J. Pharmacol. 2000, 390, 339-345. [CrossRef]

55. Broca, C.; Breil, V.; Cruciani-Guglielmacci, C.; Manteghetti, M.; Rouault, C.; Derouet, M.; Rizkalla, S.; Pau, B.; Petit, P.; Ribes, G.; et al. Insulinotropic agent ID-1101 (4-hydroxyisoleucine) activates insulin signaling in rat. Am. J. Physiol. Endocrinol. Metab. 2004, 287, E463-E471. [CrossRef] [PubMed]

56. Jaiswal, N.; Maurya, C.K.; Venkateswarlu, K.; Sukanya, P.; Srivastava, A.K.; Narender, T.; Tamrakar, A.K. 4-Hydroxyisoleucine stimulates glucose uptake by increasing surface GLUT4 level in skeletal muscle cells via phosphatidylinositol-3-kinase-dependent pathway. Eur. J. Nutr. 2012, 51, 893-898. [CrossRef] [PubMed]

57. Yu, H.; Wu, M.; Lu, F.R.; Xie, J.; Zheng, N.; Qin, Y.; Gao, F.; Du, W.; Jian, L.M. Effect of Trigonella foenum-graecum 4-hydroxyisoleucine on high-glucose induced insulin resistance in 3T3-L1 adipocytes of mice. Chin. J. Integr. Tradit. West. Med. 2013, 33, 1394-1399. 
58. Gao, F.; Du, W.; Zafar, M.I.; Shafqat, R.A.; Jian, L.; Cai, Q.; Lu, F. 4-Hydroxyisoleucine ameliorates an insulin resistant-like state in 3T3-L1 adipocytes by regulating TACE/TIMP3 expression. Drug Des. Dev. Ther. 2015, 9, 5727-5736. [CrossRef] [PubMed]

59. Hannan, J.M.; Ali, L.; Rokeya, B.; Khaleque, J.; Akhter, M.; Flatt, P.R.; Abdel-Wahab, Y.H. Soluble dietary fibre fraction of Trigonella foenum-graecum (fenugreek) seed improves glucose homeostasis in animal models of type 1 and type 2 diabetes by delaying carbohydrate digestion and absorption, and enhancing insulin action. Br. J. Nutr. 2007, 97, 514-521. [CrossRef] [PubMed]

60. Hamden, K.; Jaouadi, B.; Carreau, S.; Bejar, S.; Elfeki, A. Inhibitory effect of fenugreek galactomannan on digestive enzymes related to diabetes, hyperlipidemia, and liver-kidney dysfunctions. Biotechnol. Bioprocess. Eng. 2010, 15, 407-413. [CrossRef]

61. Eastwood, M.; Kritchevsky, D. Dietary fiber: How did we get where we are? Annu. Rev. Nutr 2005, 25, 1-8. [CrossRef] [PubMed]

62. Verma, N.; Usman, K.; Patel, N.; Jain, A.; Dhakre, S.; Swaroop, A.; Bagchi, M.; Kumar, P.; Preuss, H.G.; Bagchi, D. A multicenter clinical study to determine the efficacy of a novel fenugreek seed (Trigonella foenum-graecum) extract (Fenfuro) in patients with type 2 diabetes. Food Nutr. Res. 2016, 60, 32382. [CrossRef] [PubMed]

63. Drolet, M.-C.; Plante, E.; Battistini, B.; Couet, J.; Arsenault, M. Early endothelial dysfunction in cholesterol-fed rabbits: A non-invasive in vivo ultrasound study. Cardiovasc. Ultrasound 2004, 2, 10. [CrossRef] [PubMed]

64. Garcia-Prieto, C.F.; Hernández-Nuño, F.; Rio, D.D.; Ruiz-Hurtado, G.; Aránguez, I.; Ruiz-Gayo, M.; Somoza, B.; Fernández-Alfonso, M.S. High-fat diet induces endothelial dysfunction through a down-regulation of the endothelial AMPK-PI3K-Akt-eNOS pathway. Mol. Nutr. Food Res. 2015, 59, 520-532. [PubMed]

65. Chinen, I.; Shimabukuro, M.; Yamakawa, K.; Higa, N.; Matsuzaki, T.; Noguchi, K.; Ueda, S.; Sakanashi, M.; Takasu, N. Vascular lipotoxicity: Endothelial dysfunction via fatty-acid-induced reactive oxygen species overproduction in obese Zucker diabetic fatty rats. Endocrinology 2007, 148, 160-165. [CrossRef] [PubMed]

66. Li, H.; Li, H.; Bao, Y.; Zhang, X.; Yu, Y. Free fatty acids induce endothelial dysfunction and activate protein kinase $C$ and nuclear factor-kappaB pathway in rat aorta. Int. J. Cardiol. 2011, 152, 218-224. [CrossRef] [PubMed]

67. Schächinger, V.; Britten, M.B.; Zeiher, A.M. Prognostic Impact of Coronary Vasodilator Dysfunction on Adverse Long-Term Outcome of Coronary Heart Disease. Circulation 2000, 101, 1899-1906. [CrossRef] [PubMed]

68. Bertoluci, M.C.; Cé, G.V.; da Silva, A.M.; Wainstein, M.V.; Boff, W.; Puñales, M. Endothelial dysfunction as a predictor of cardiovascular disease in type 1 diabetes. World J. Diabetes 2015, 6, 679-692. [CrossRef] [PubMed]

69. Vázquez-Rey, E.; Kaski, J.C. Cardiovascular Syndrome X and Endothelial Dysfunction. Rev. Española de Cardiol. (Engl. Ed.) 2003, 56, 181-192. [CrossRef]

70. Furchgott, R.F.; Zawadzki, J.V. The obligatory role of endothelial cells in the relaxation of arterial smooth muscle by acetylcholine. Nature 1980, 288, 373-376. [CrossRef] [PubMed]

71. Palmer, R.M.; Ferrige, A.; Moncada, S. Nitric oxide release accounts for the biological activity of endothelium-derived relaxing factor. Nature 1987, 327, 524-526. [CrossRef] [PubMed]

72. Buchwalow, I.B.; Cacanyiova, S.; Neumann, J.; Samoilova, V.E.; Boecker, W.; Kristek, F. The role of arterial smooth muscle in vasorelaxation. Biochem. Biophys. Res. Commun. 2008, 377, 504-507. [CrossRef] [PubMed]

73. Azevedo, L.C.; Pedro, M.A.; Souza, L.C.; de Souza, H.P.; Janiszewski, M.; da Luz, P.L.; Laurindo, F.R. Oxidative stress as a signaling mechanism of the vascular response to injury: The redox hypothesis of restenosis. Cardiovasc. Res. 2000, 47, 436-445. [CrossRef]

74. Motulsky, H.; Christopoulos, A. Fitting Models to Biological Data Using Linear and Nonlinear Regression: A Practical Guide to Curve Fitting; Oxford University Press: Oxford, UK, 2004.

75. Gesztelyi, R.; Zsuga, J.; Kemeny-Beke, A.; Varga, B.; Juhasz, B.; Tosaki, A. The Hill equation and the origin of quantitative pharmacology. Arch. Hist. Exact Sci. 2012, 66, 427-438. [CrossRef]

(C) 2018 by the authors. Licensee MDPI, Basel, Switzerland. This article is an open access article distributed under the terms and conditions of the Creative Commons Attribution (CC BY) license (http:/ / creativecommons.org/licenses/by/4.0/). 